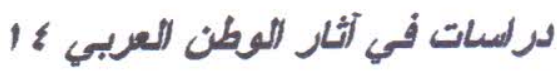

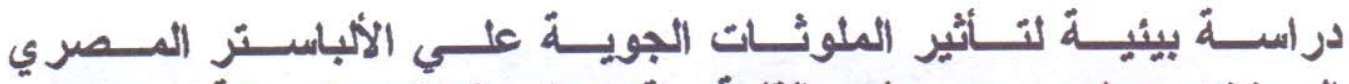

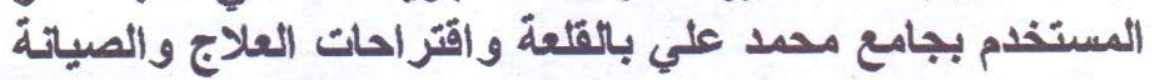

أ.م.د. عبده عبداللاه الدربي" أ.د. باوي محمد إبماعيل ** د.عصام حشمت محمد"**

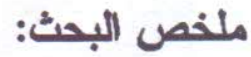

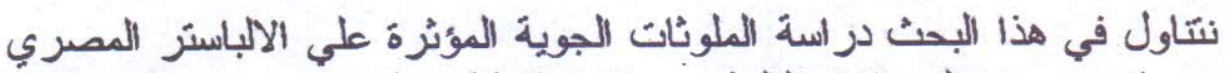

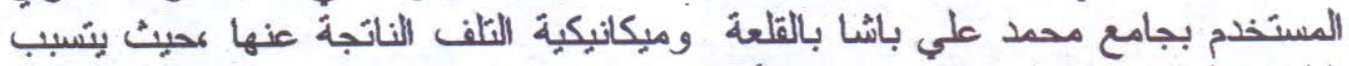

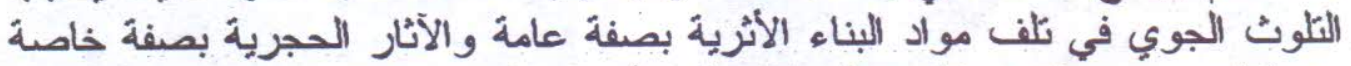

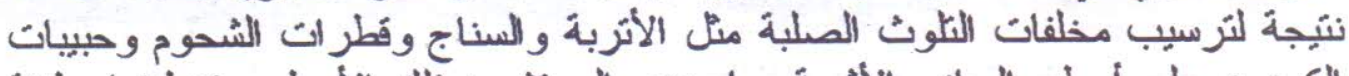

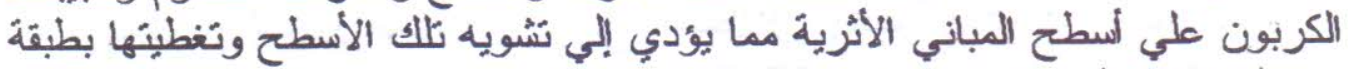

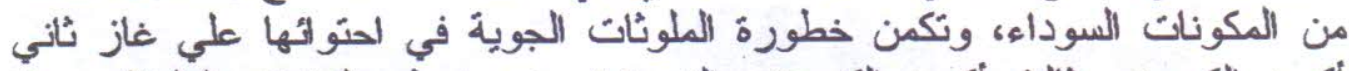

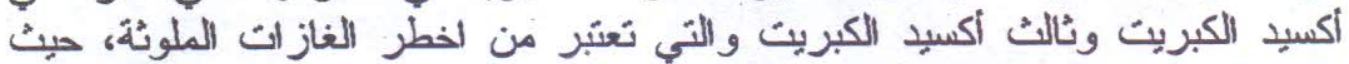

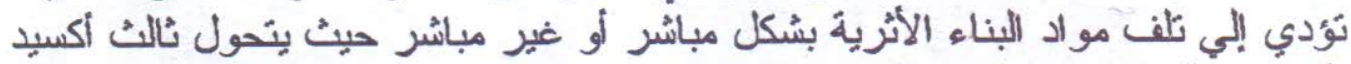

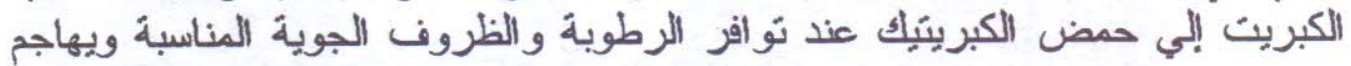

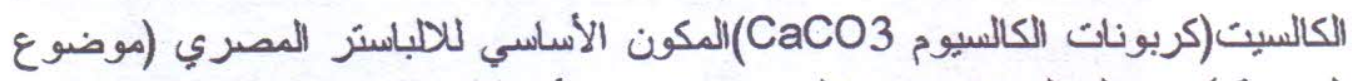

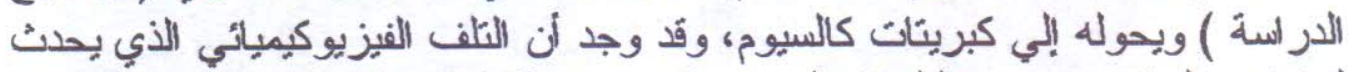

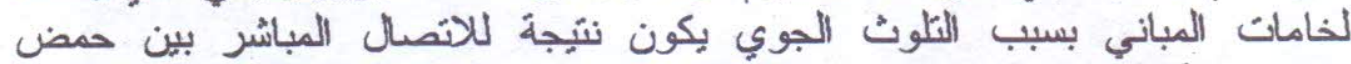

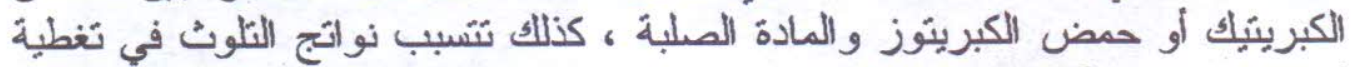

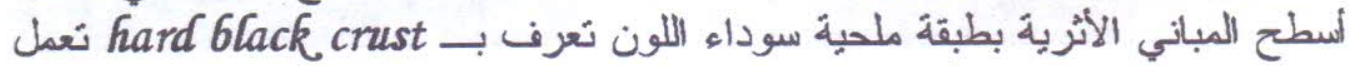

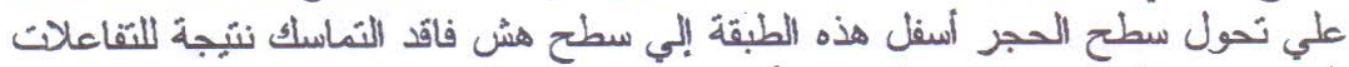

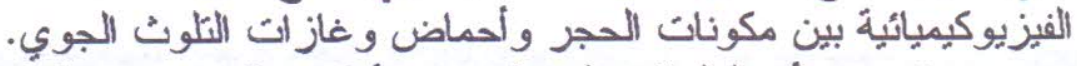

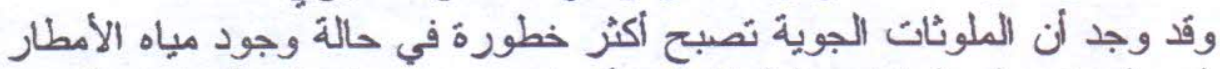

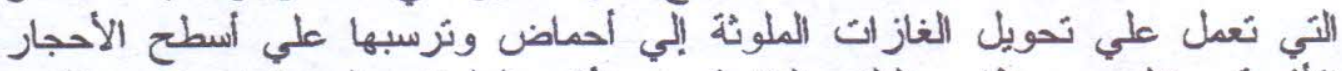

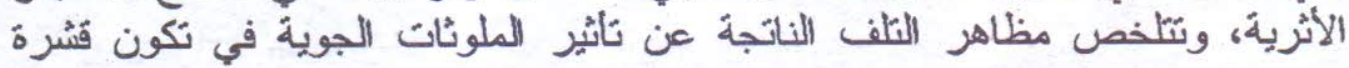

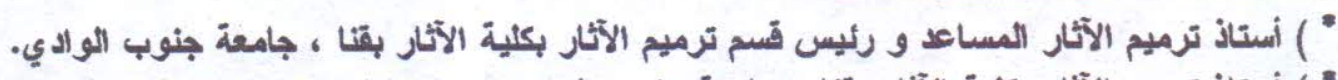

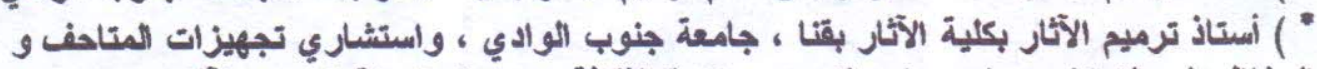

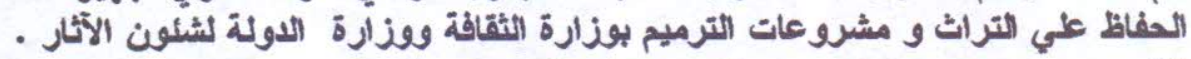

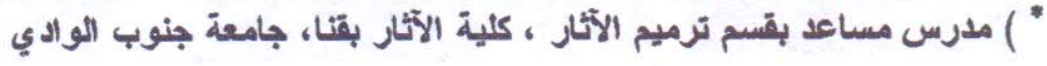




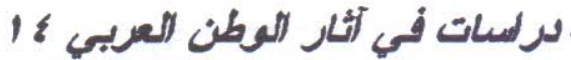

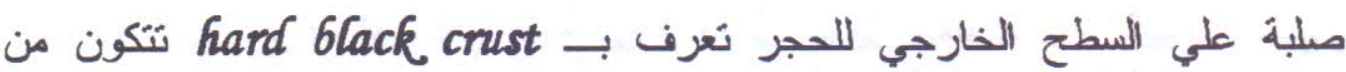

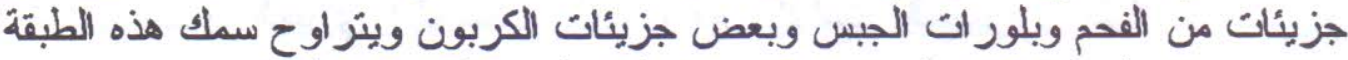

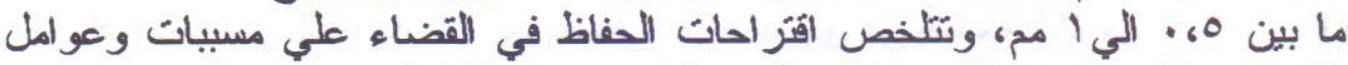

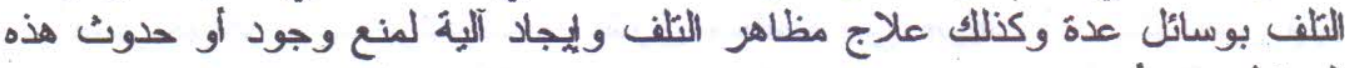

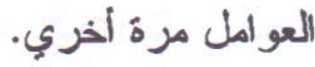

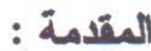

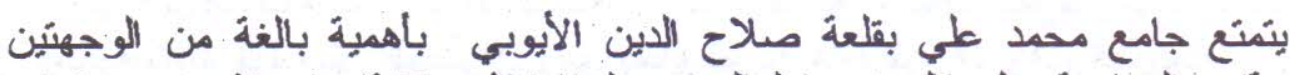

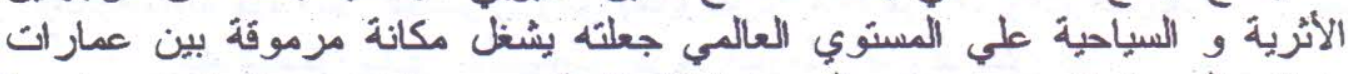

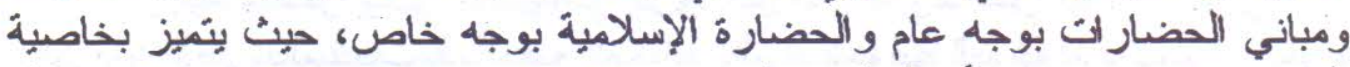

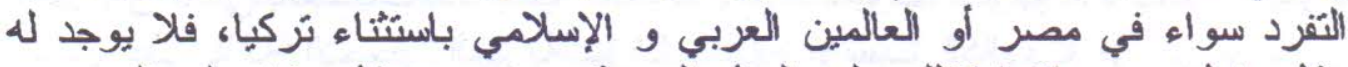

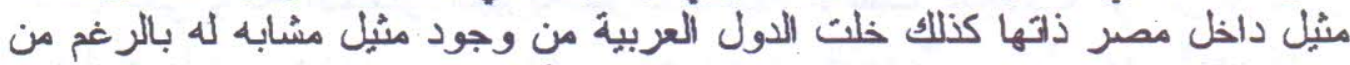

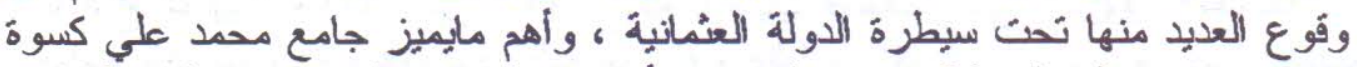

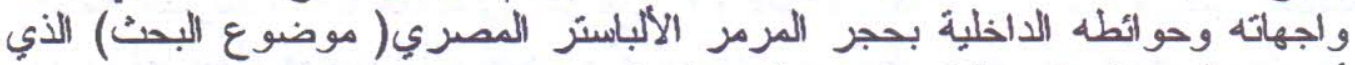

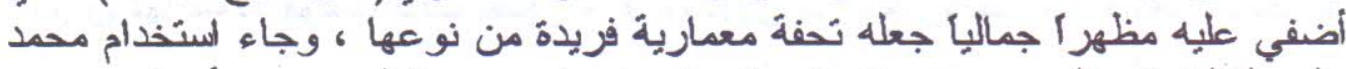

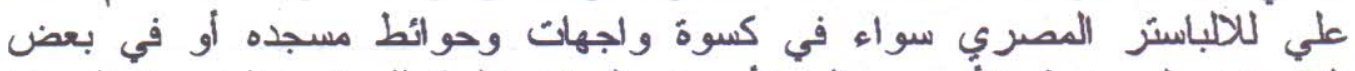

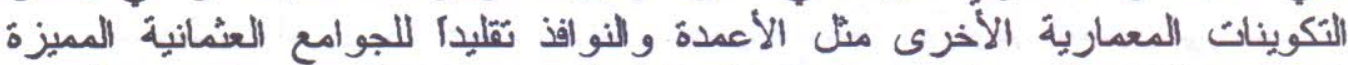

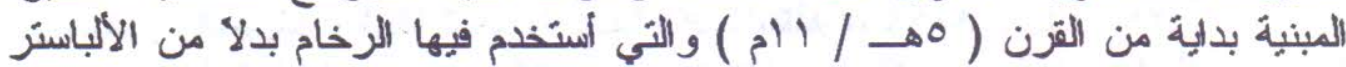

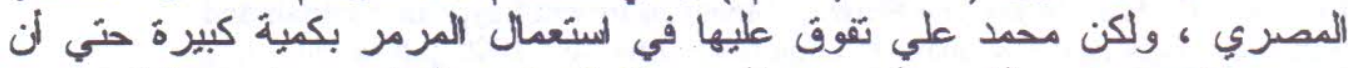

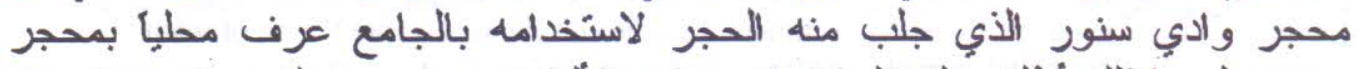

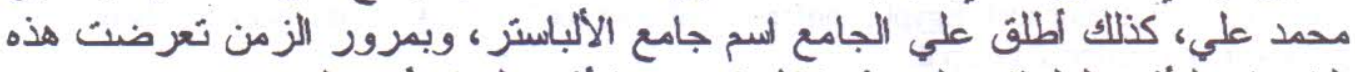

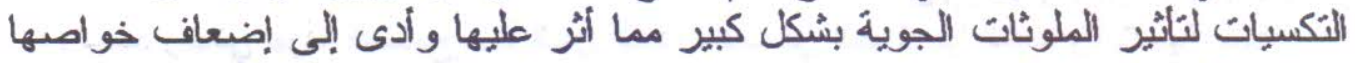

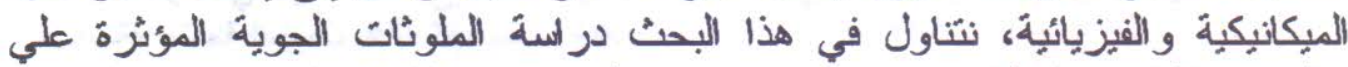

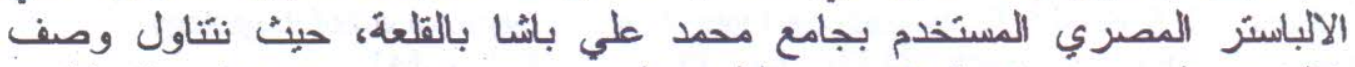

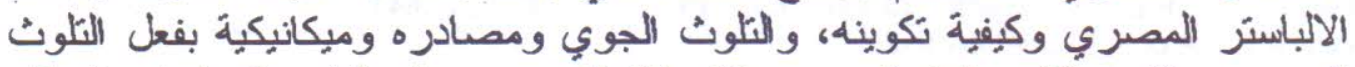

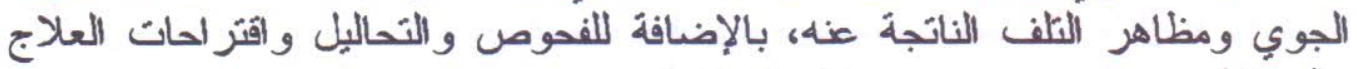

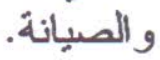

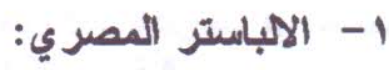

ينتمي صخر الألباستر المصري إلي الصخور الرسوبية كيميائية النشاة وهو (كرئي

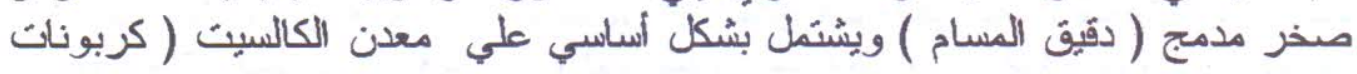

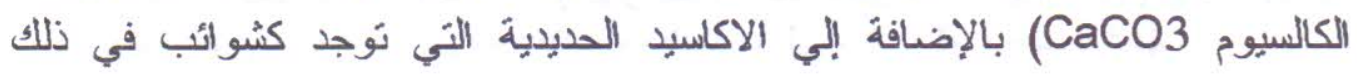




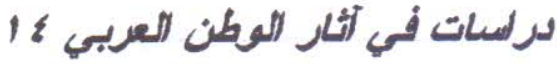

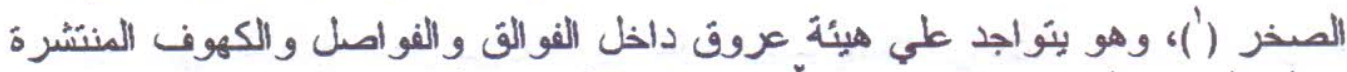

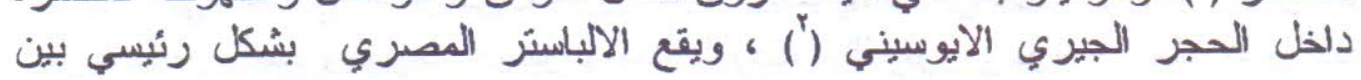

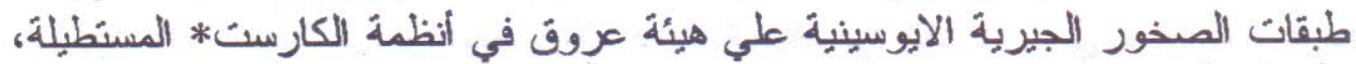

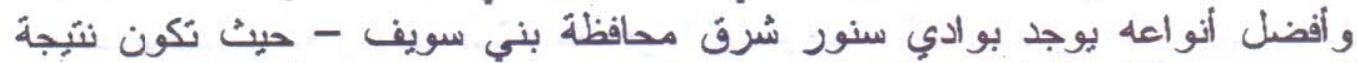

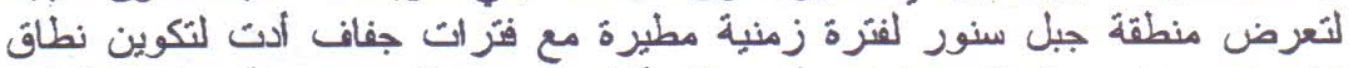

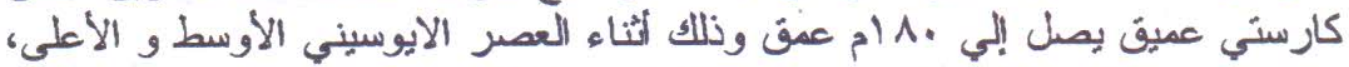

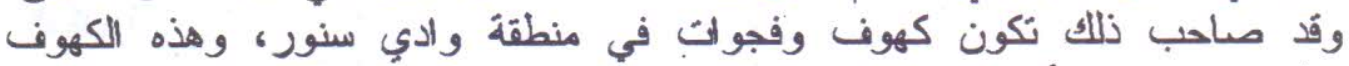

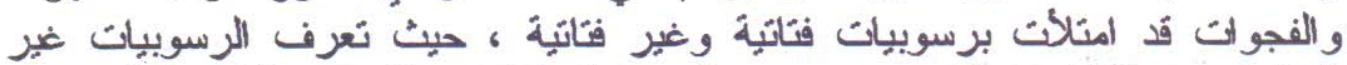

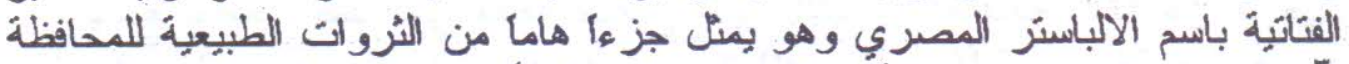

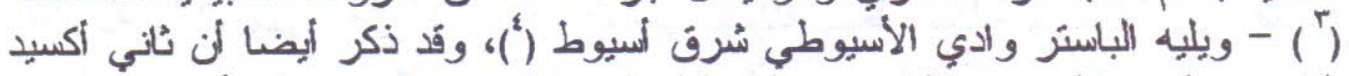

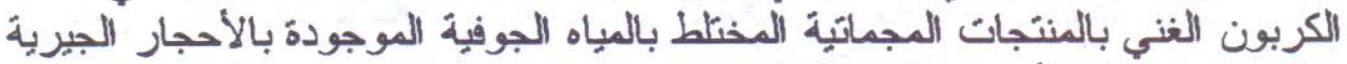

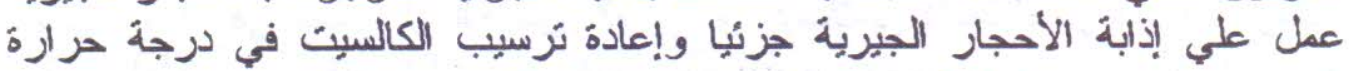

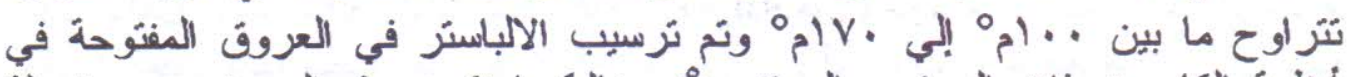

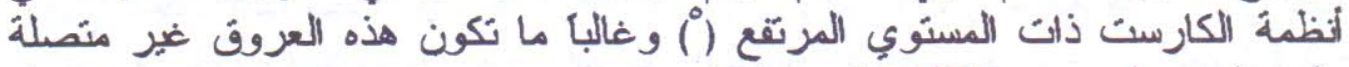

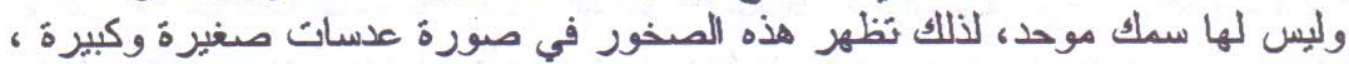

(1) و .د.هاملتون وآخرون ، ترجمة محمد فتحي عوض ، المعجم الجيولوجي المصور في المعانن

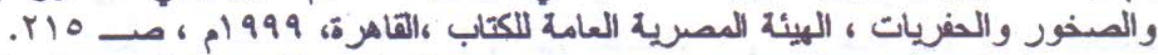
2) Aston, B.G., Harrell, J.A. and Shaw, I., Stone, in, ancient Egyptian materials and technology, Nicholson.T \& Shaw, I., Cambridge university, 2000, p.p.59- 60.

3) Ewais, S.G., ., geological and environmental studies on the protectorate area of wadi sannur, south east bent suef ,Egypt , conference of beni suef, faculty of arts, branch of bent suef, Cairo university, 2002, p.2.

ع) محمد رجائي جودة \& سامع سعد الين احمد، مقمة في الجيولوجيا العامة والهنسية، كلية

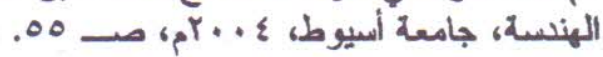

5) Klemm, D. \& Klemm, R., the building stones of ancient Egypt - a gift of its geology, journal of African earth science 33,631-642, E1 Sevier, 2001, P. 641,

www.elsevier.com/locate/jafrearsci.

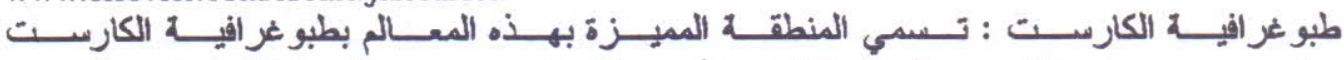
Karst topography

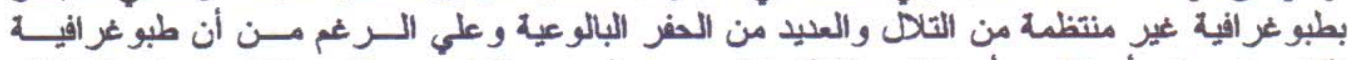

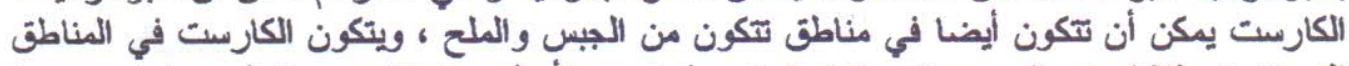

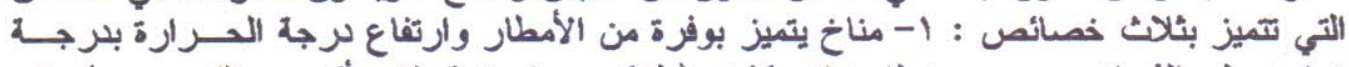

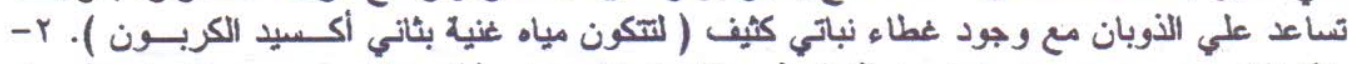

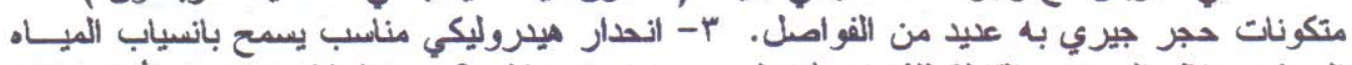

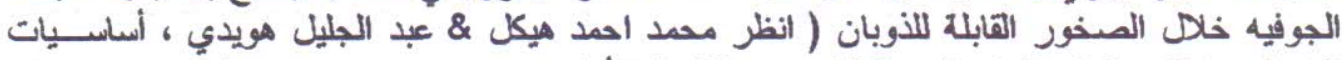

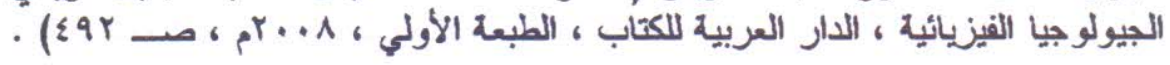




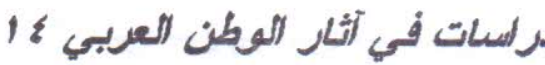

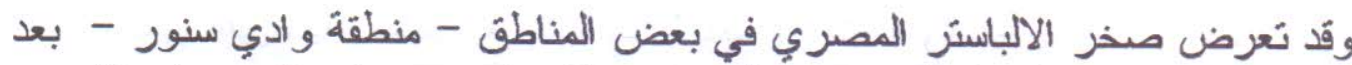

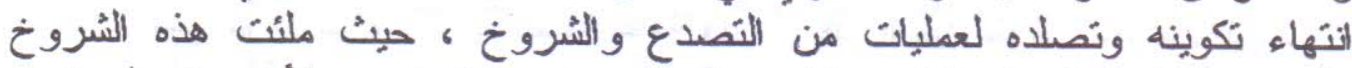

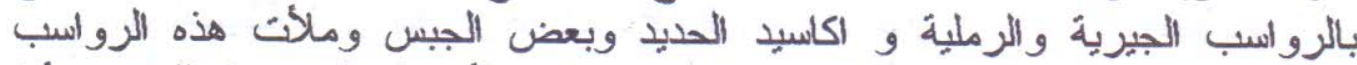

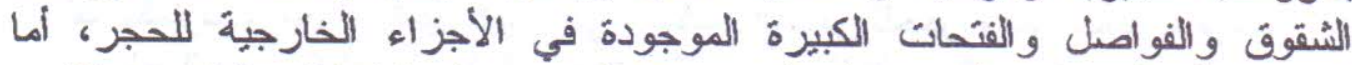

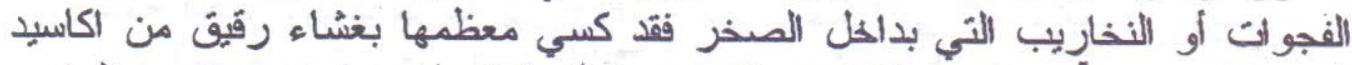

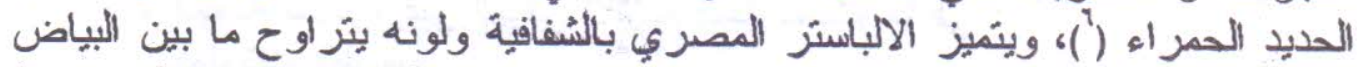

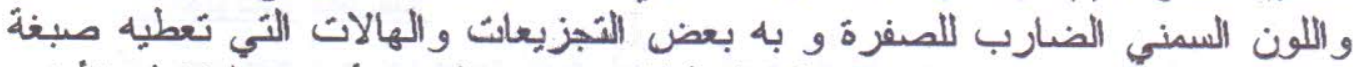

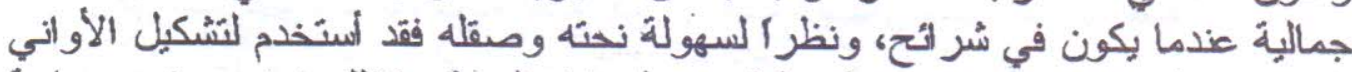

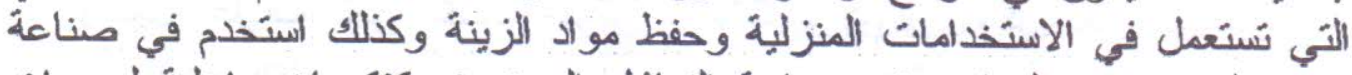

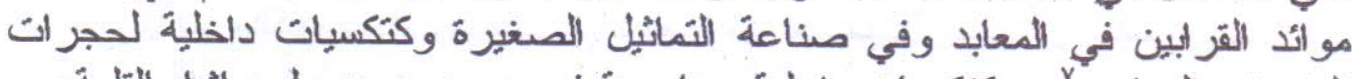

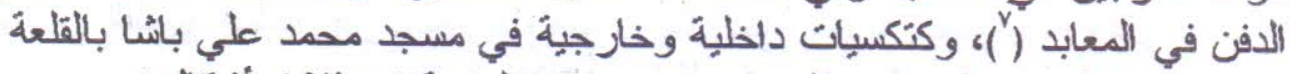

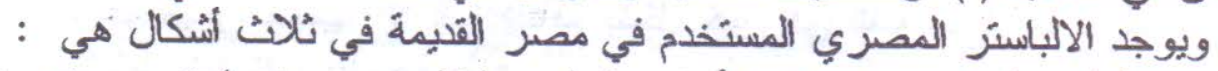

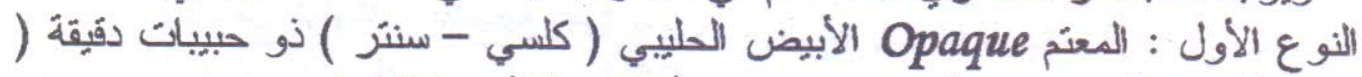

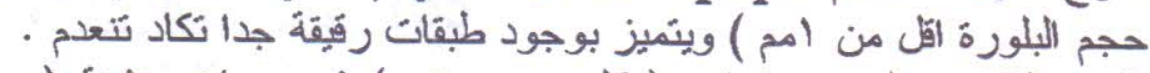

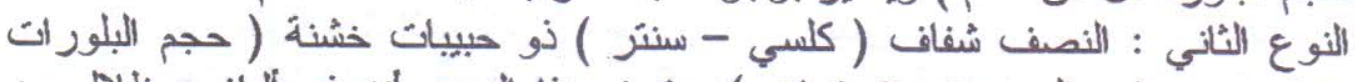

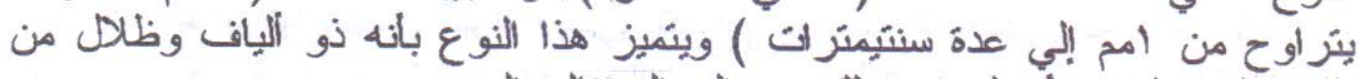

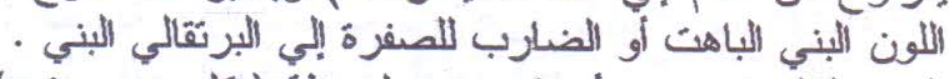

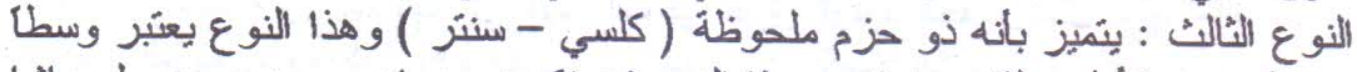

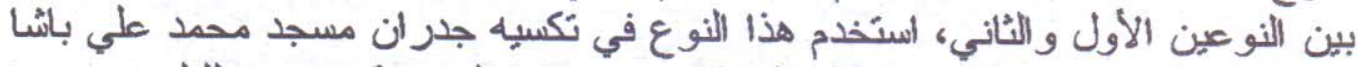

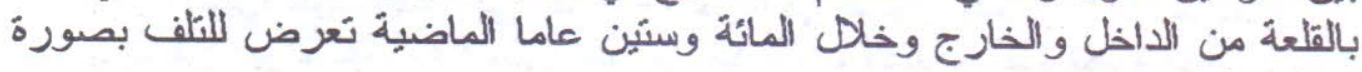

\section{Air Pollution}

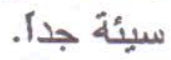

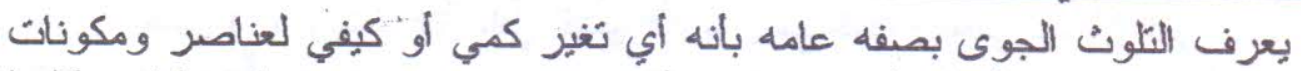

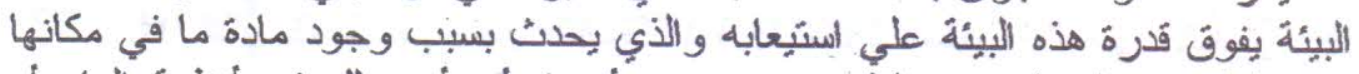

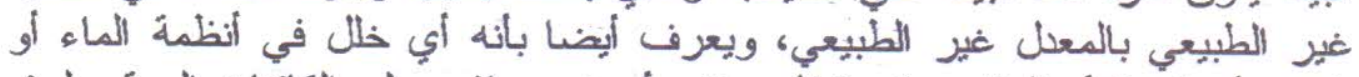

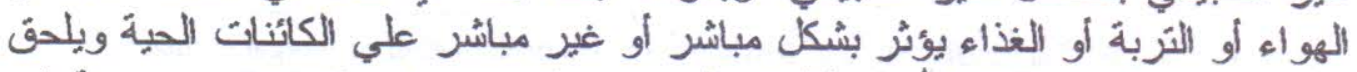

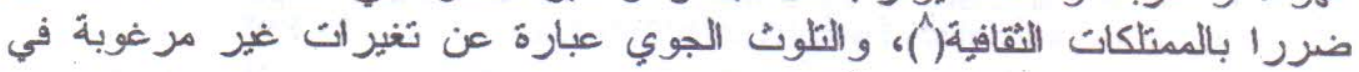

6) E1.Hinnawi, E. E. \& Loukina, S. M., A contribution to the geochemistry of " Egyptian alabaster ", TMPM Tsehermaks Min. Petr. Mitt. 17, 215--221, Springer-Verlag , 1972, p.217.

7) Soliman,N.F., Investigation of an Egyptian alabaster ore by measuring its natural radioactivity and by NAA using K0 standardization and comparator methods, journal of nuclear and radiation physics, Vol.1, No.1, 2006, P.32.

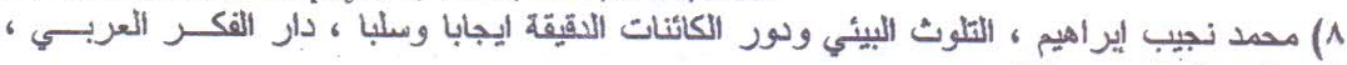

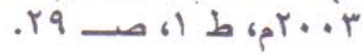




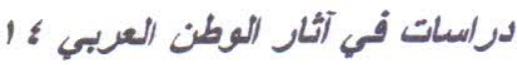

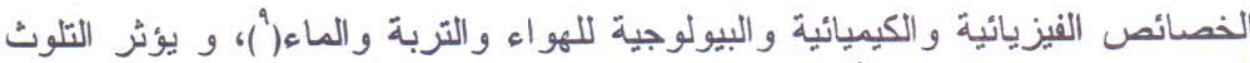

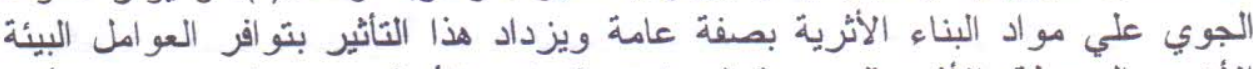

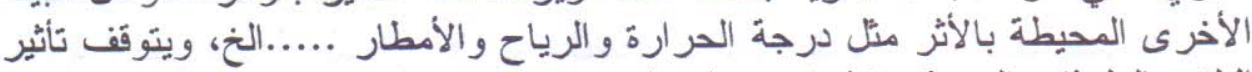

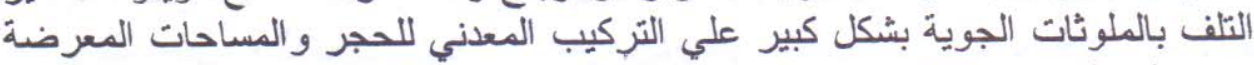

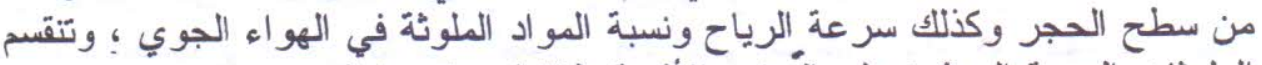

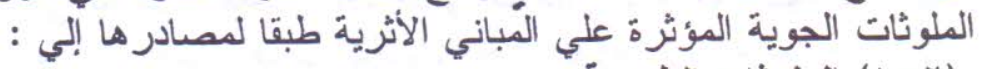

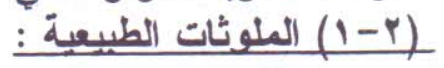

وهي تللك الملوثات الموجودة أصلا في التركيب الطبيعي للجو المحبط بصفة دائمة

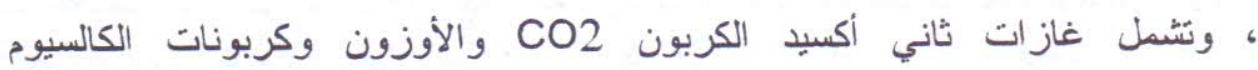

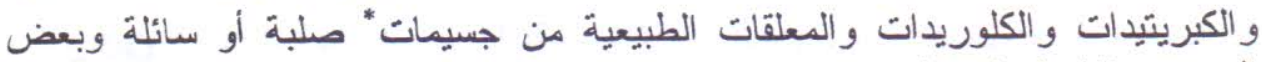

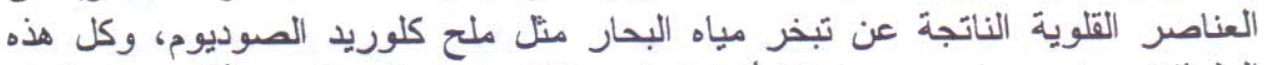

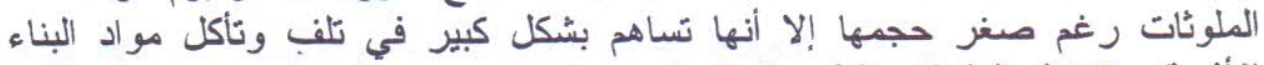

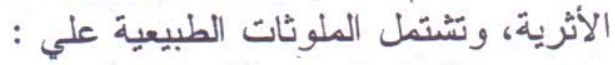

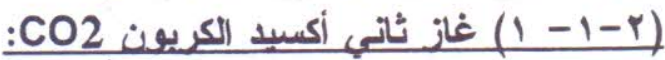

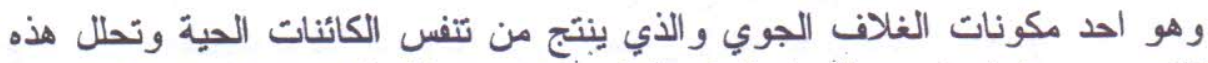

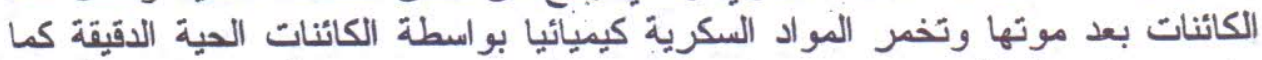

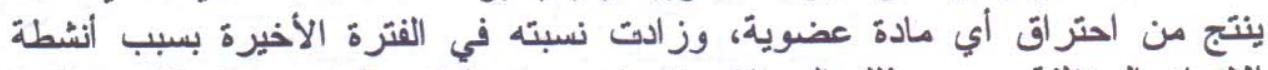

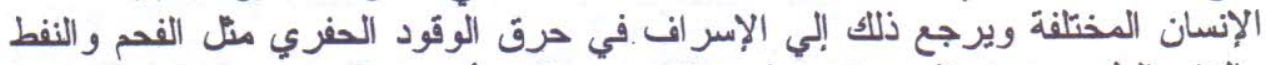

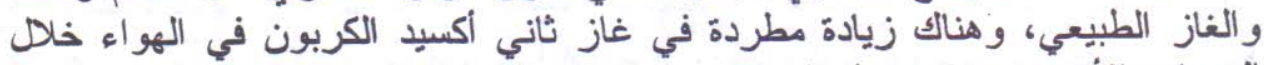

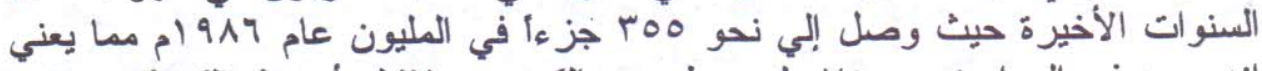

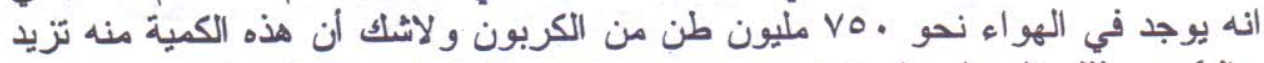

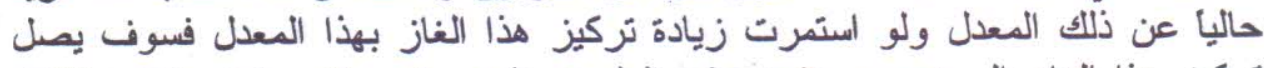

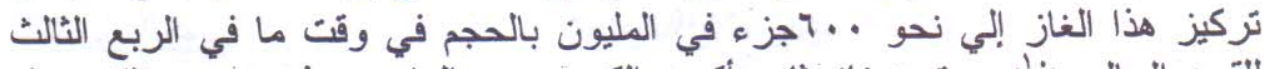

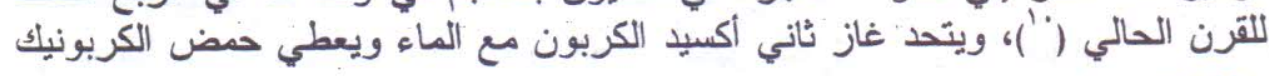
H2CO3 الذي يتفاعل مع معدن الكالسيت ( ( CaCO3 المكون الأساسي الالباستر

9) Caneva, G., Pia nugari, M., and Salvadori, O., Biodeterioration of inorganic materials, in: Biology in the conservation of works of art, ICCROM, Roma, Italy, 1991, P.93.

* تعرف الجسيمات بأنها ما يحمله الهواء من جزيئات صلبة أو سائلة تنطلق إليه من مصادر عديدة

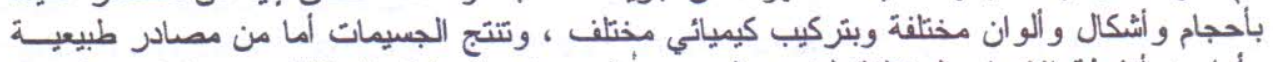

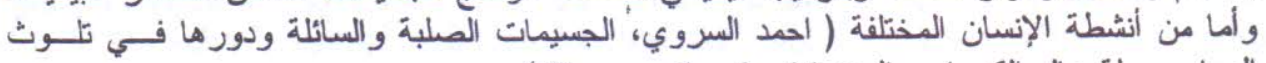

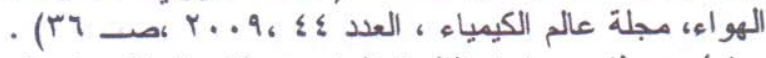

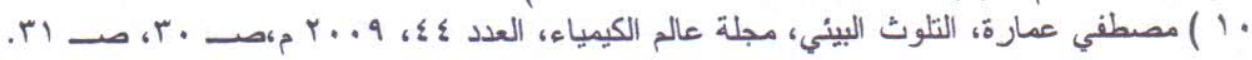




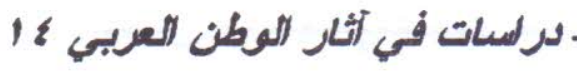

المصري ( موضوع الدراسة ) ويحوله إلب بيكربونات كالسيوم 2 Ca(HCO3 قابلة للإبان في الماء

$\mathrm{CO}_{2}+\mathrm{H}_{2} \mathrm{O}$

$\mathrm{H}_{2} \mathrm{CO}_{3}$

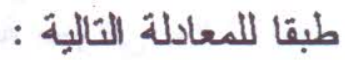

\section{$\mathrm{CaCO} 3+\mathrm{H}_{2} \mathrm{CO}_{3}$}

\section{$\mathrm{Ca}\left(\mathrm{HCO}_{3}\right)_{2}$ بيكريونت كلايوم تلبلة للذويلن في}

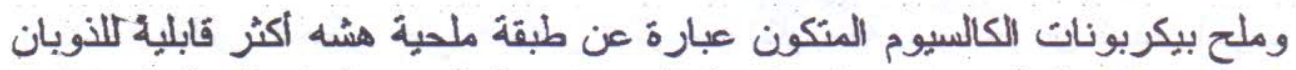

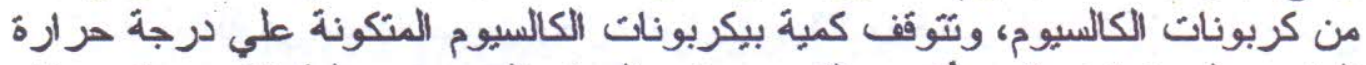

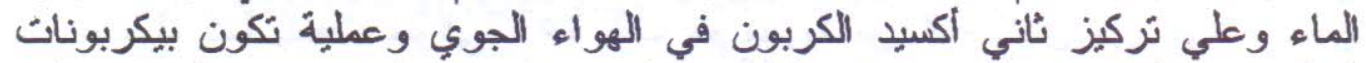

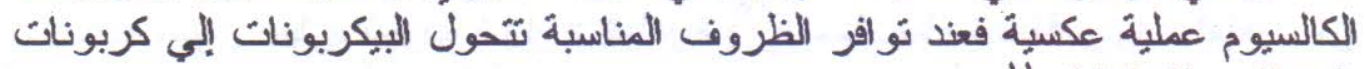
طبقا للمعادلة التالية (")

\section{$\mathrm{Ca}\left(\mathrm{HCO}_{3}\right)_{2}$}

\section{$\mathrm{CaCO}_{3}+\mathrm{CO}_{2}+\mathrm{H}_{2} \mathrm{O}$}

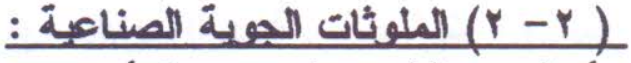

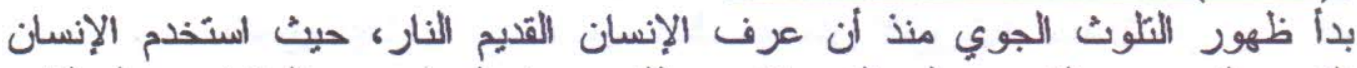

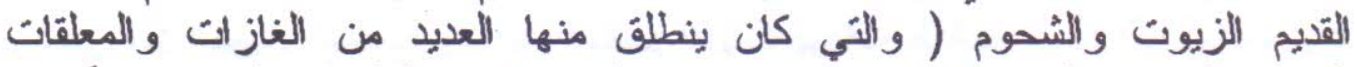

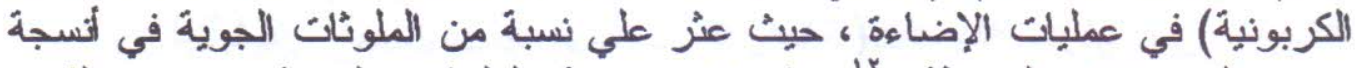

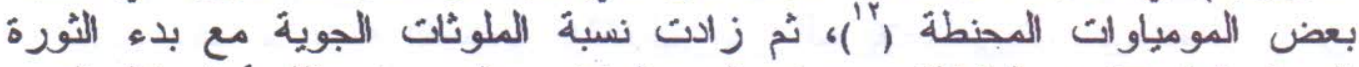

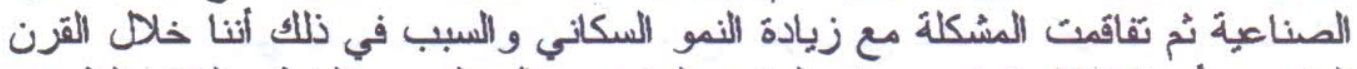

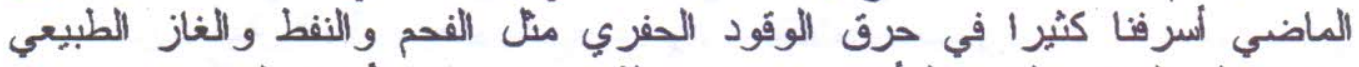
ورفعنا إلي الغلاف الجوي للأرض كميات هائلة من غاز ثاني أكسيد الكربون وغان الغاز الطيات

11) Rovnanikova, P., environmental pollution effects on other building material in, environmental deterioration of materials , Moncmanova, A., Southampton, Boston, 2007, P. 223.

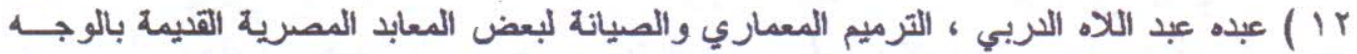

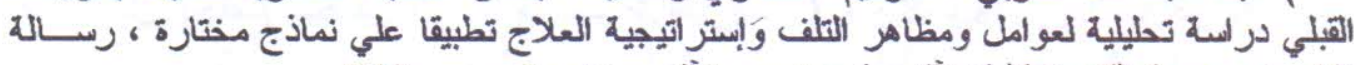

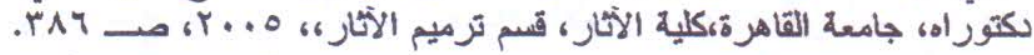

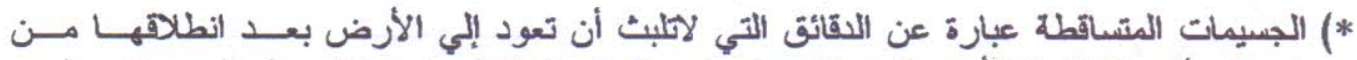

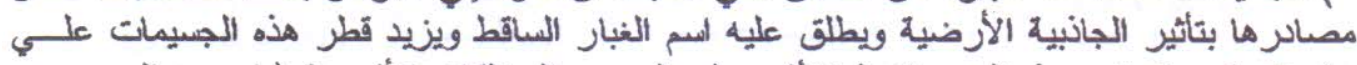

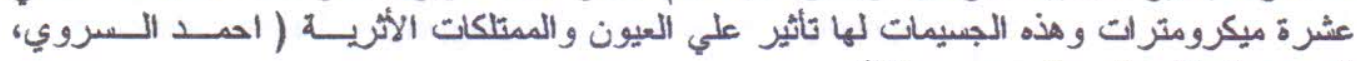

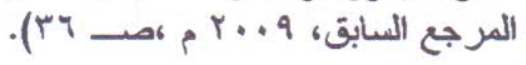




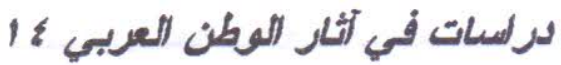

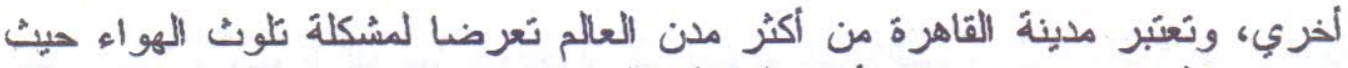

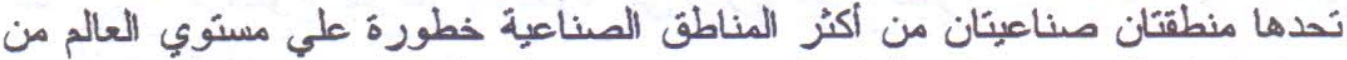

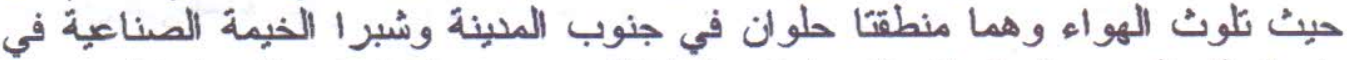

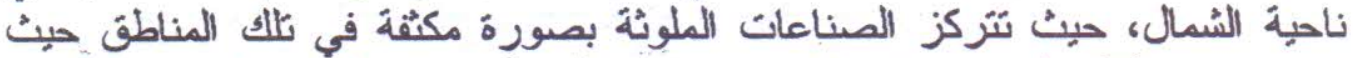

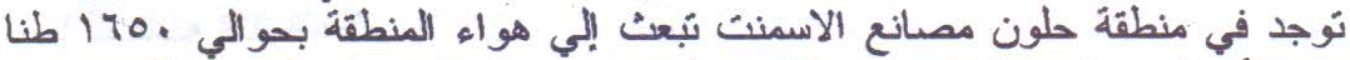

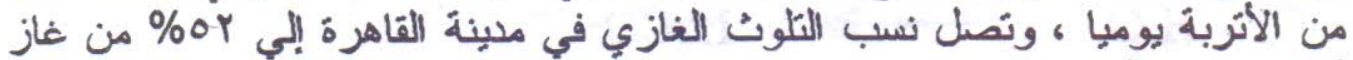

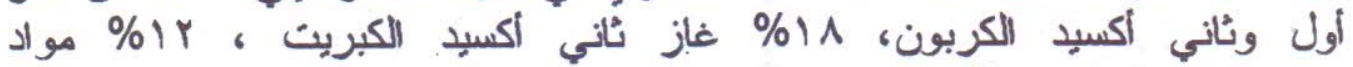

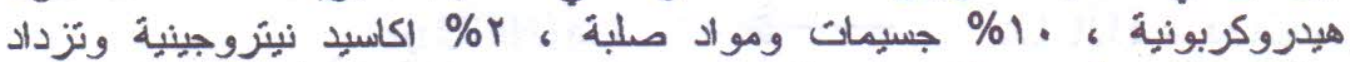

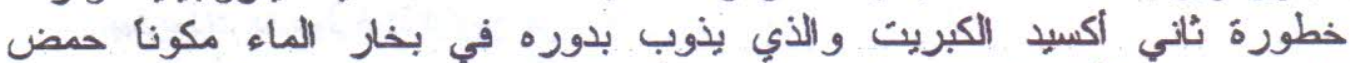

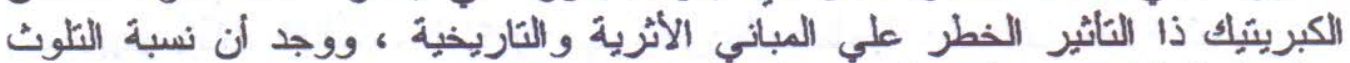

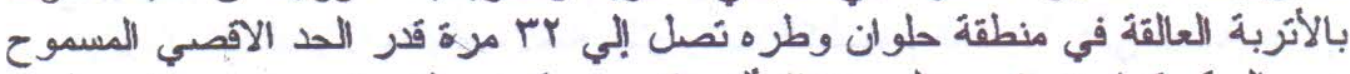

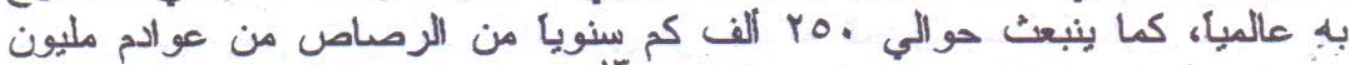

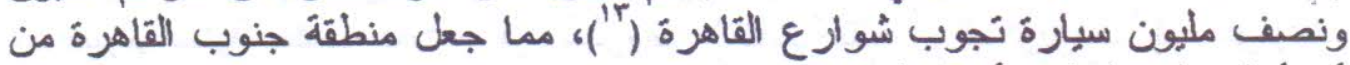

\section{: SOX} أسوأ المناطق تلوناً بالأتربة المتساقطة

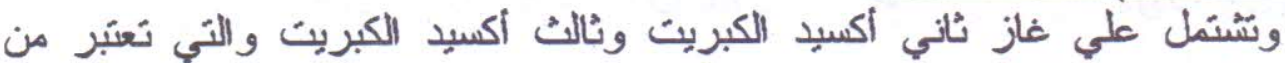

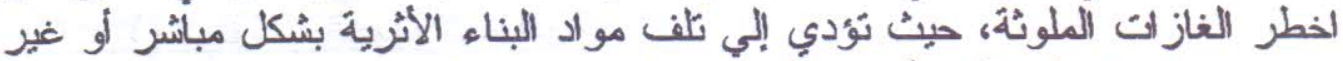

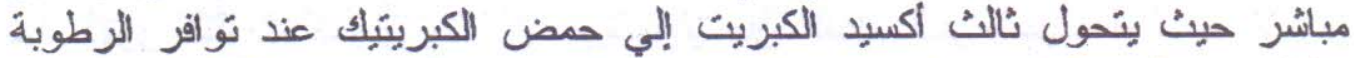
والظروف الجوية المناسبة وبهاجم الكالسيت ( كربونات الكات الكالسيوم CaCO3) المكون

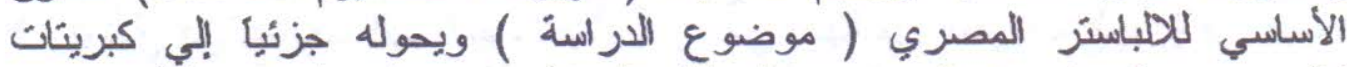

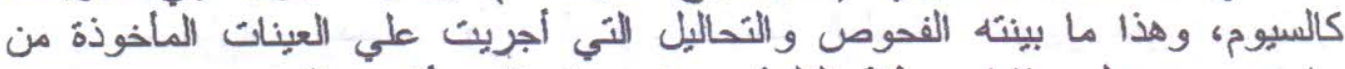

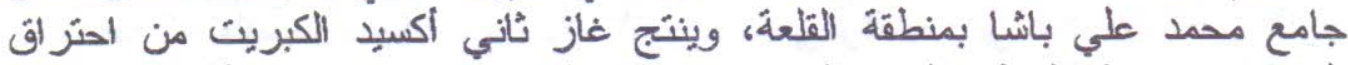

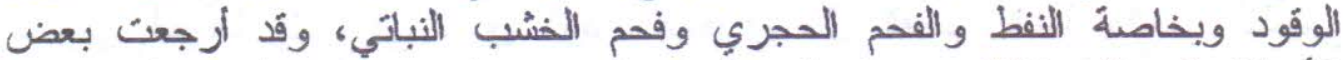

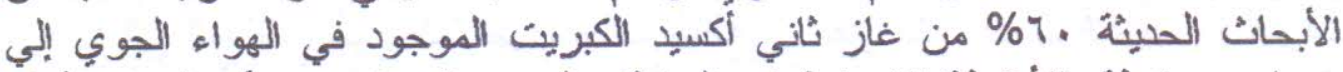

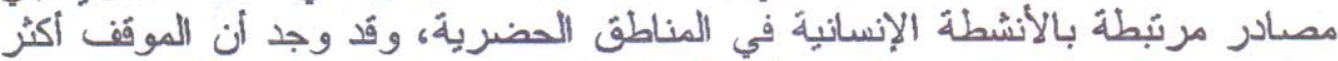

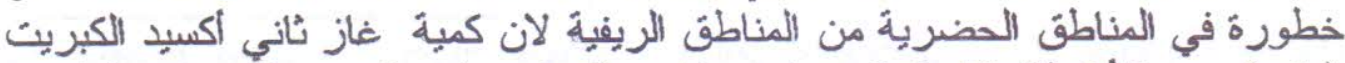

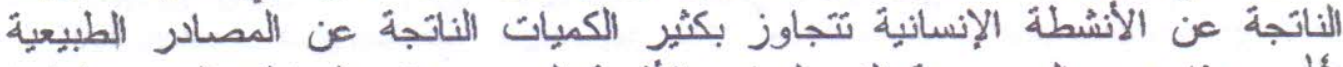

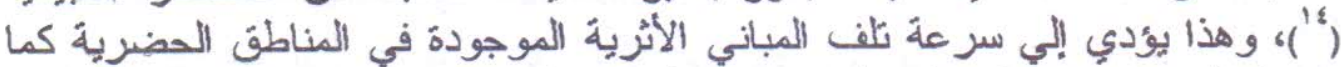

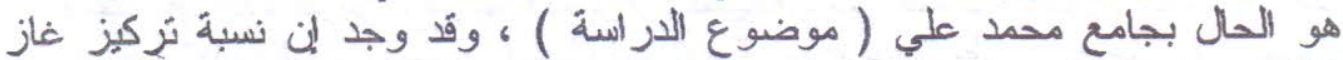

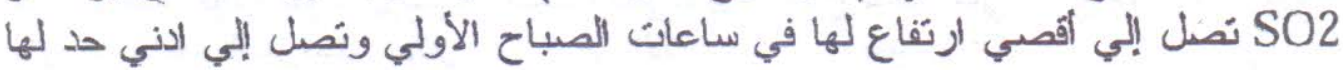

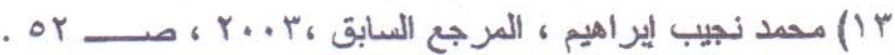
14) Fassina,V.,Pollution atmospherique et alteration de la pierre , La degradation et la conservation de la pierre , $1991, \mathrm{p} 91$. 


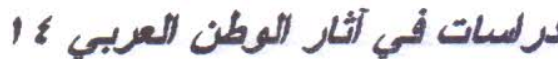

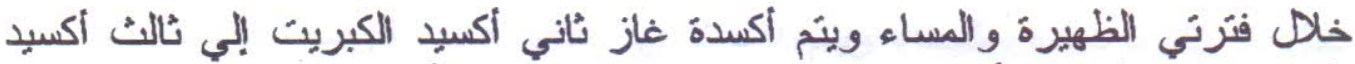

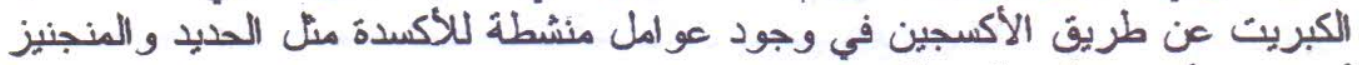
أو معان أخرى طبقا لإن المعادلة

\section{$2 \mathrm{SO} 2+\mathrm{O}^{2}$}

\section{$2 \mathrm{SO} 3$}

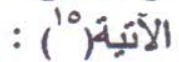

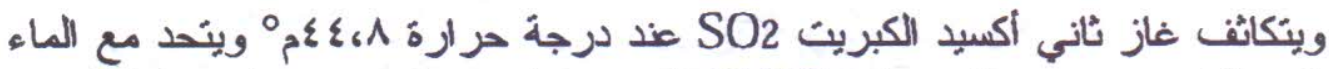

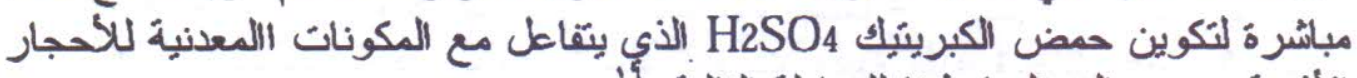

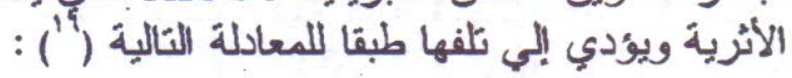

\section{$\mathrm{CaCO} 3+\mathrm{SO} 2+1 / 2 \mathrm{H} 2 \mathrm{O} \rightarrow \mathrm{CaSO} 3 \cdot 1 / 2 \mathrm{H} 2 \mathrm{O}+\mathrm{CO} 2$ (1)}

\section{$\mathrm{CaSO} 3 \cdot 1 / 2 \mathrm{H} 2 \mathrm{O}+1 / 2 \mathrm{O} 2 \rightarrow \mathrm{CaSO} \cdot 2 \mathrm{H} 2 \mathrm{O}$}

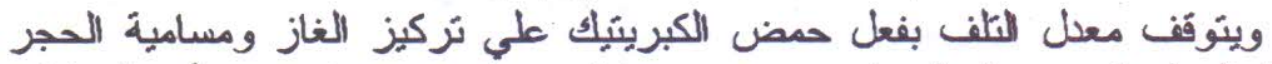

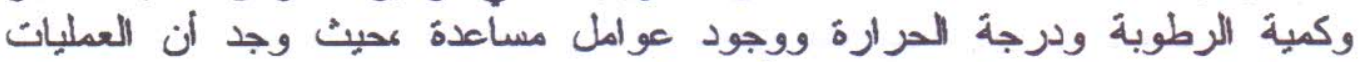

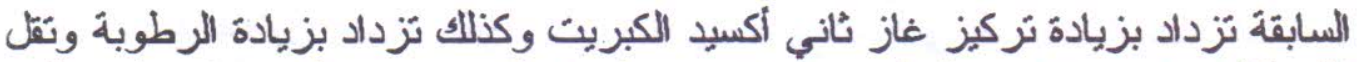

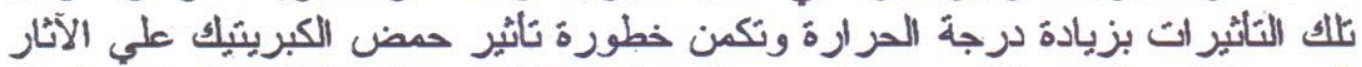

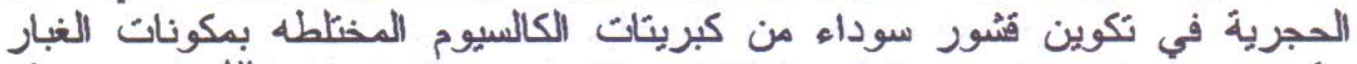

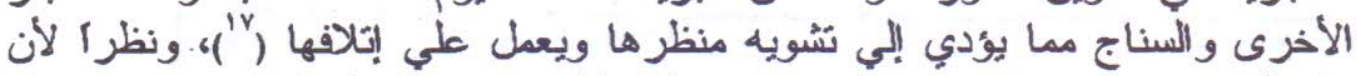

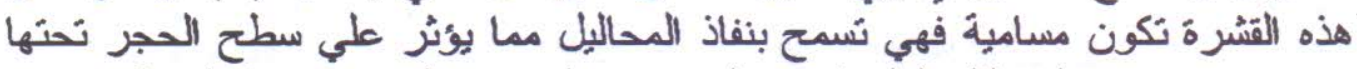

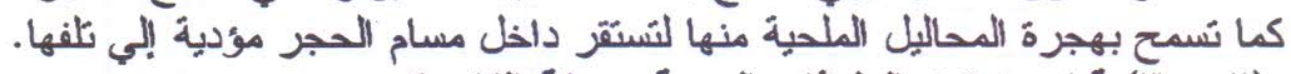

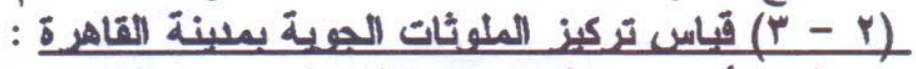

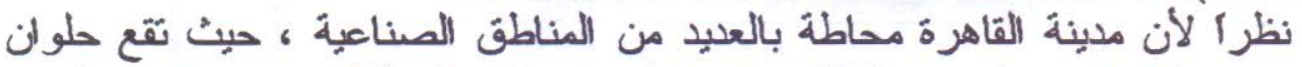

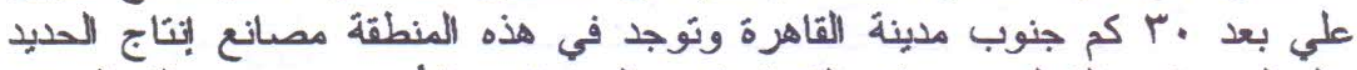

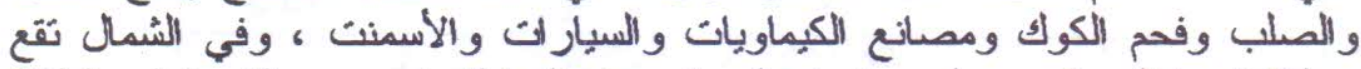

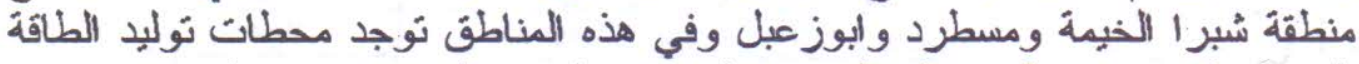

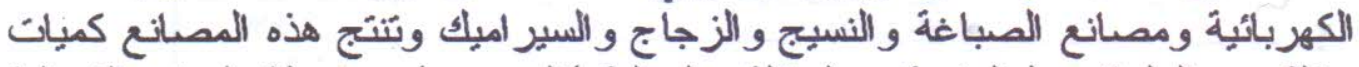

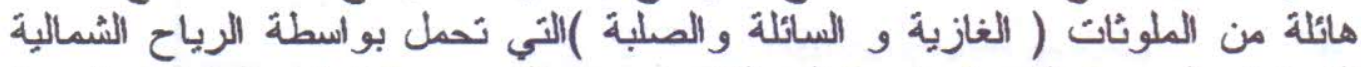

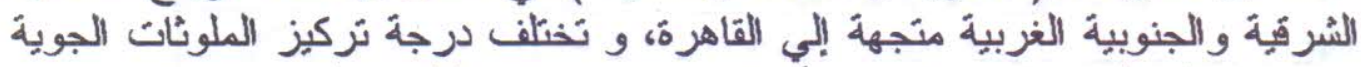

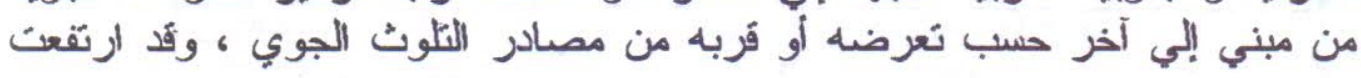

15) Rovnanikova, P. ,Op.Cit , 2007, P. 223.

16) Yilmaz and et.al., Protection of marble surfaces by using biodegradable polymers as coating agent, Progress in organic coating 66, $213-220,2009$, p.213. www.elsevier.com -

17) Fassina ,V. , Op.Cit , 1991 , p 92. 


\section{دراسات في آثار الوطن العربي ؛ 1 ألوب}

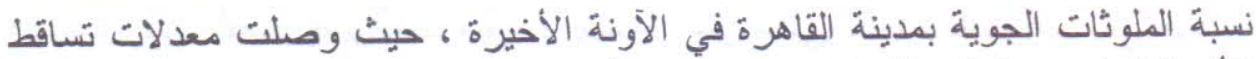

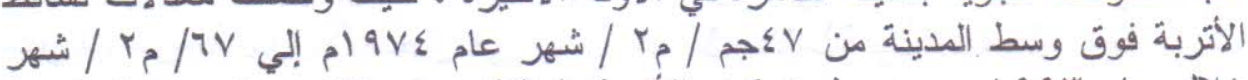

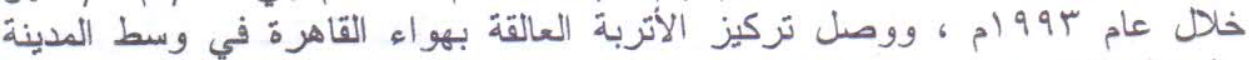

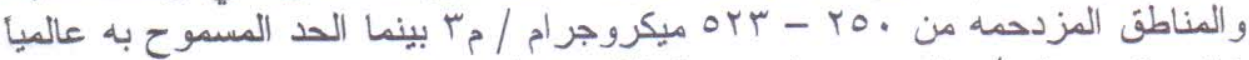

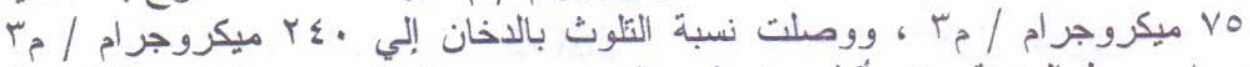

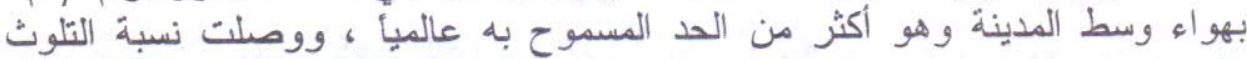

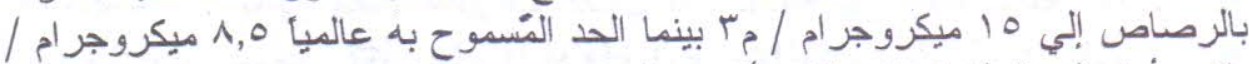

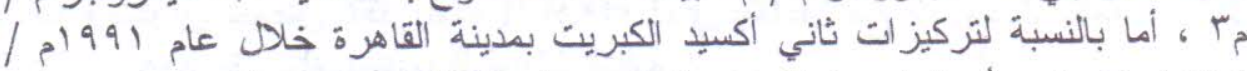
بو ام فقد تبين أن المتوسط الشهري لتركيز غاز

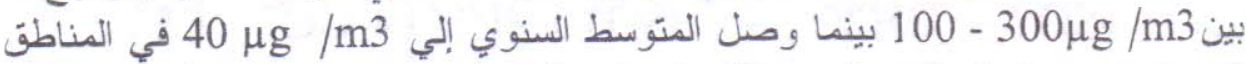

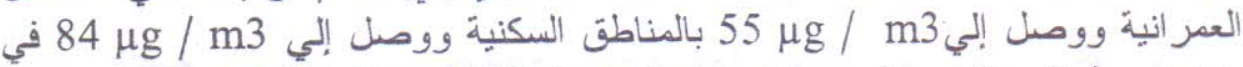

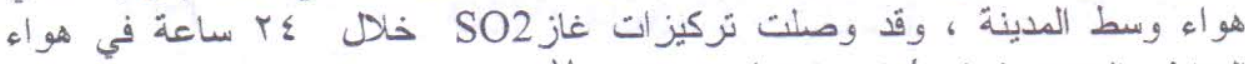

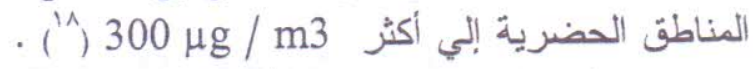

جدول رقم (rV) يبين الحد المسموح به من الملوثات الجوية بهو اء مدينة القاهرة

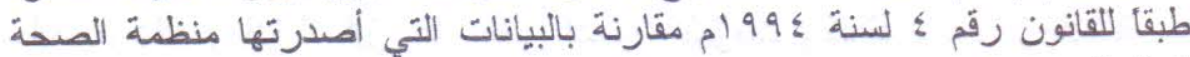

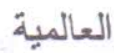

World Health Orgạnization (WHO)

\begin{tabular}{|c|c|c|}
\hline Pollutant & Maximum Limit & $\begin{array}{c}\text { Averaging } \\
\text { Time }\end{array}$ \\
\hline Sulfur Dioxide $\left(\mathrm{SO}_{2}\right)$ & $350 \mathrm{ug} / \mathrm{m}^{2}$ & 1 Hour \\
\hline 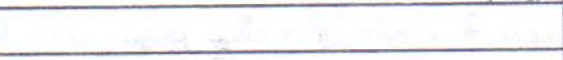 & $150 \mu \mathrm{g} / \mathrm{m}^{3}$ & 24 Hour \\
\hline & $60 \mu \mathrm{\mu} / \mathrm{m}^{3}$ & Annual \\
\hline Carbon Monoxide $(C O)$ & $30 \mathrm{mg} / \mathrm{m}^{3}$ & 1 Hour \\
\hline & $10 \mathrm{mg} / \mathrm{m}^{3}$ & 8 Hour \\
\hline Nitrogen Dioxide $\left(\mathrm{NO}_{2}\right)$ & $400 \mu \mathrm{g} / \mathrm{m}^{3}$ & 1 Hour \\
\hline & $150 \mu \mathrm{g} / \mathrm{m}^{3}$ & 24 Hour \\
\hline Ozone $\left(\mathrm{O}_{3}\right)$ & $200 \mu \mathrm{g} / \mathrm{m}^{3}$ & 1 Hour \\
\hline & $120 \mu \mathrm{g} / \mathrm{m}^{3}$ & 8 Hour \\
\hline Black Smoke (BS) & $150 \mu \mathrm{g}^{2} \mathrm{~m}^{3}$ & 24 Hour \\
\hline & $60 \mu \mathrm{g} / \mathrm{m}^{3}$ & Annual \\
\hline Total Suspended Particulate (TSP) & $230 \mu \mathrm{g} / \mathrm{m}^{3}$ & 24 Hour \\
\hline & $90 \mu \mathrm{g} / \mathrm{m}^{3}$ & Anmual \\
\hline Suspended Particulate (PM10) & $70 \mu \mathrm{g} m^{3}$ & 24 Hour \\
\hline Lead $(\mathrm{Pb})$ & $1 \mu \mathrm{g} / \mathrm{m}^{3}$ & Annual \\
\hline
\end{tabular}

18) Sivertsen, B., A study of air pollutants during episodes, ICEHM , Egypt, , Page 345 - 361, Cairo University, September 2000, P.P.348 - 349 . 
بيسّبب اللأوث الجوي في تلف مواد البناء الأثربة بصفة عامة والآثار الحجرية

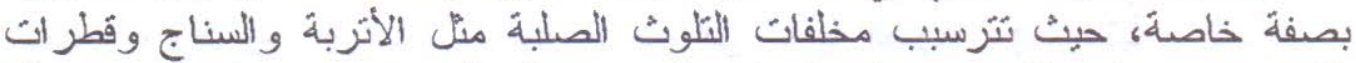

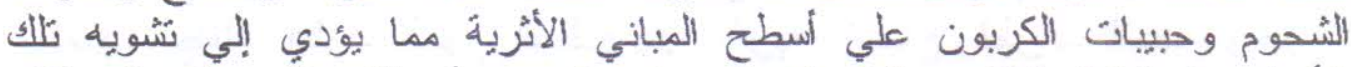

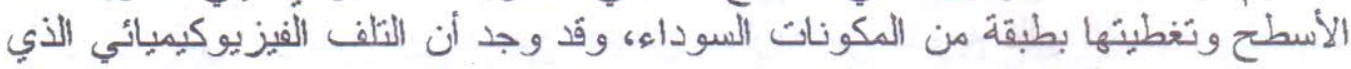

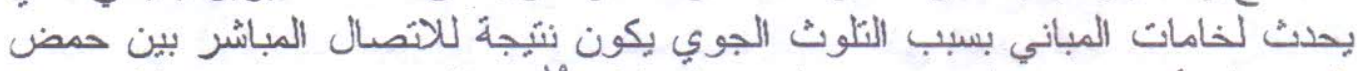

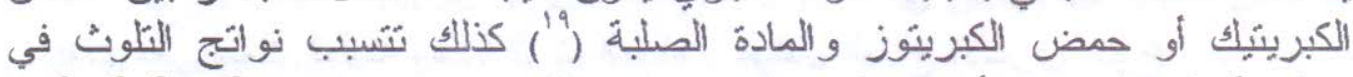

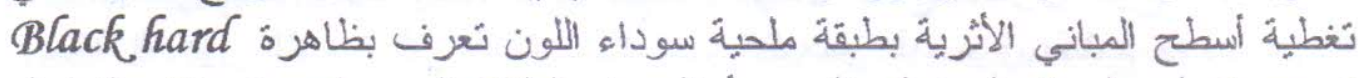
crust

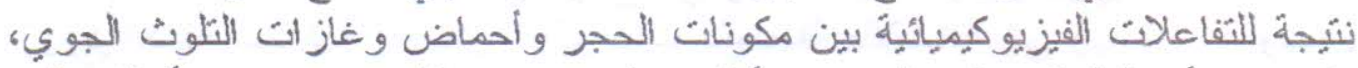

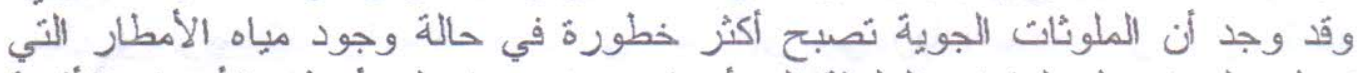

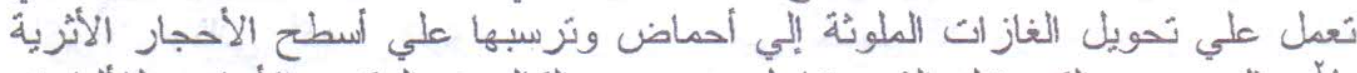
(r)

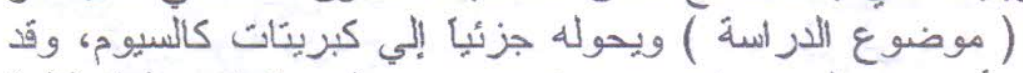

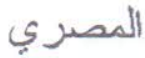

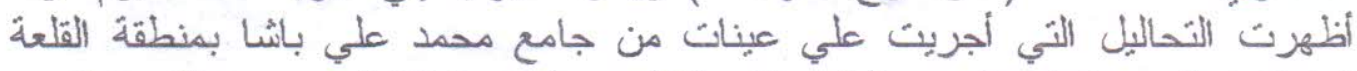

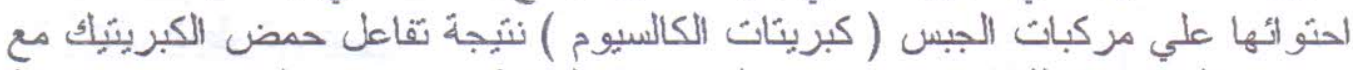

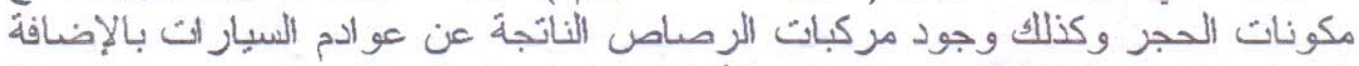

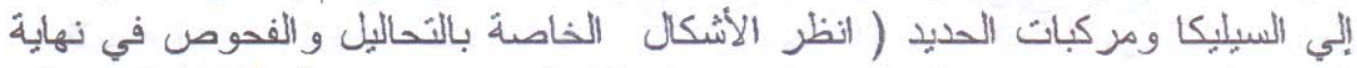

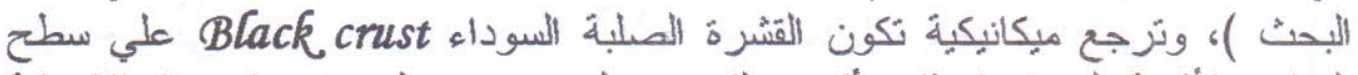

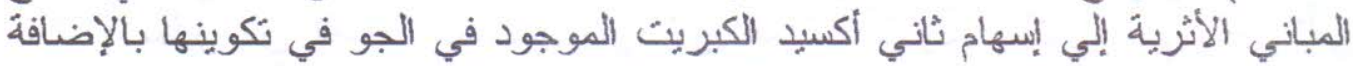

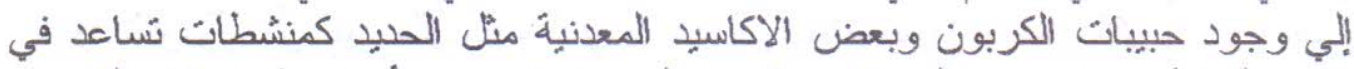

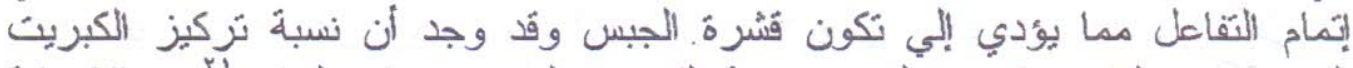

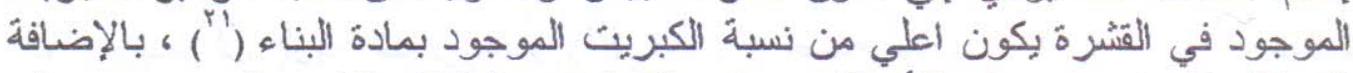

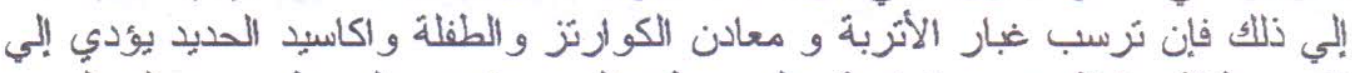

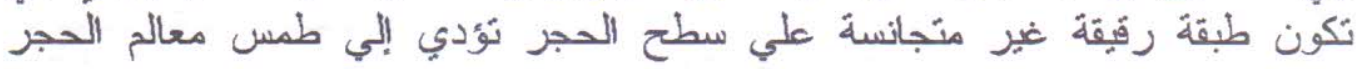

19) Abd Elhady, M., Ground water and the deterioration of Islamic building in Egypt, in the conference of (the restoration and conservation of Islamic monuments in Egypt), AUC, 1995, p.118.

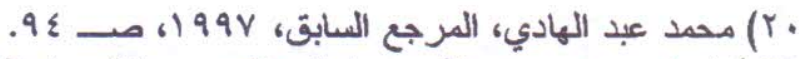

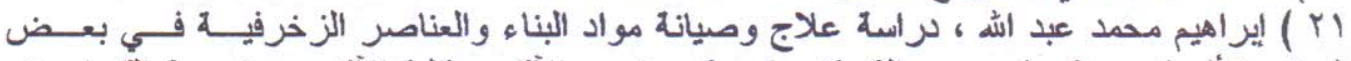

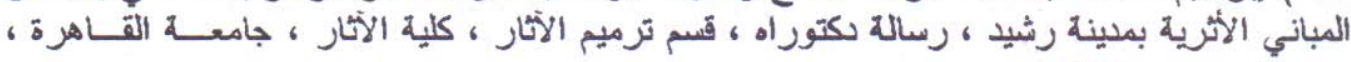

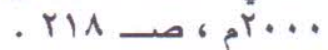
Ericsson, T., and Nord, A, G., Chemical analysis of thin black layers on building stone in " Studies in conservation " 38, 1993, P.P.25-35. 


\section{دراسات في أثار الموطن العربي 1 المئ}

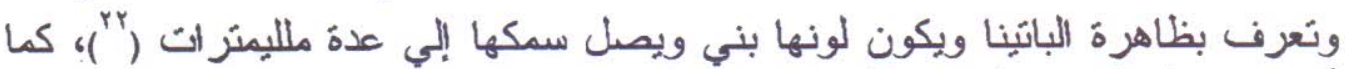

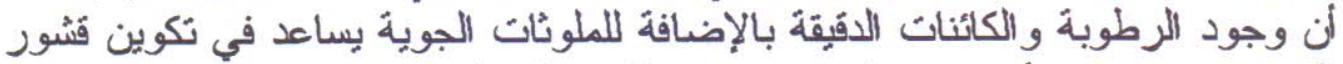

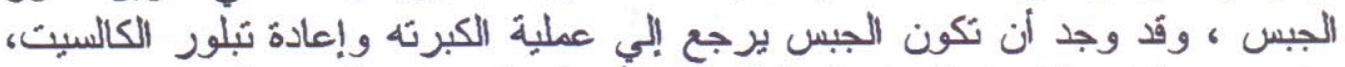

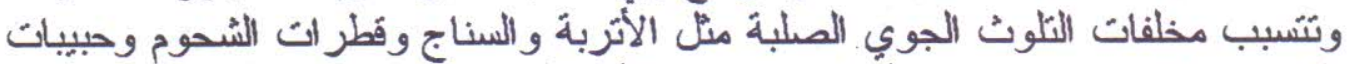

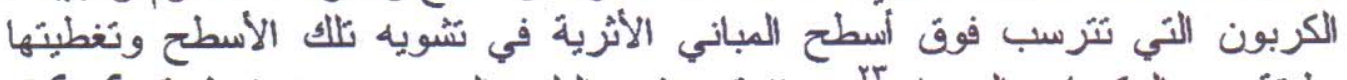

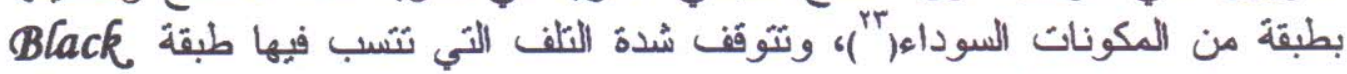
crust

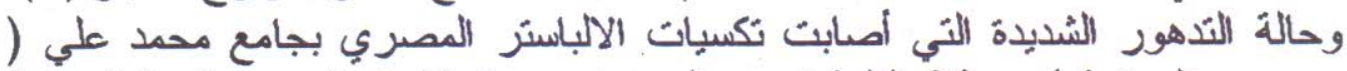

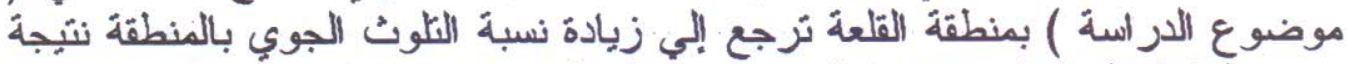

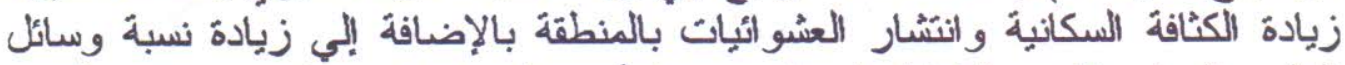

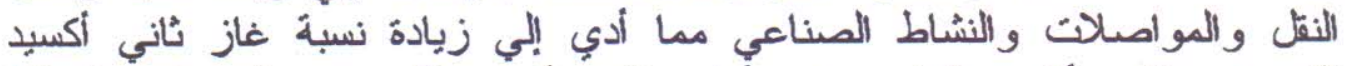

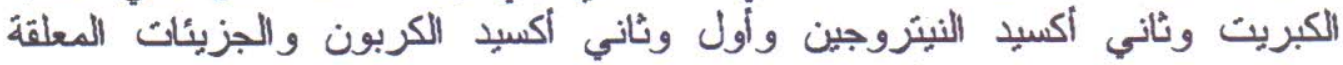

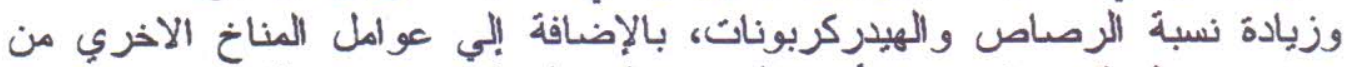

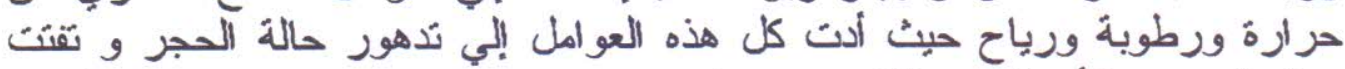
وسقوط بعض الأجز اء من التكسيات. ب- بأثبر المطر الحمضي:

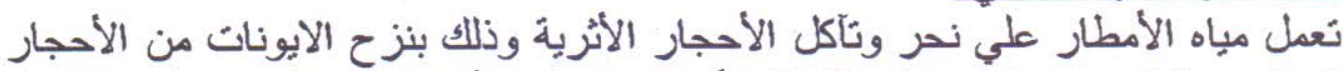

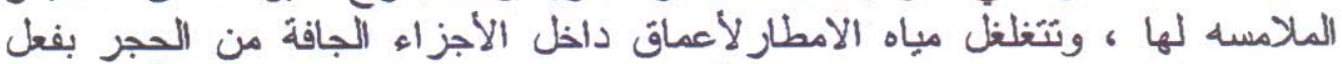

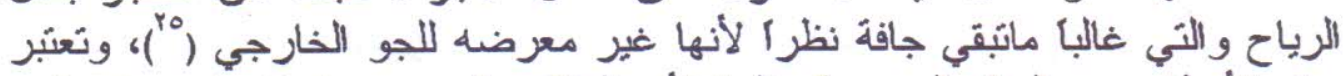

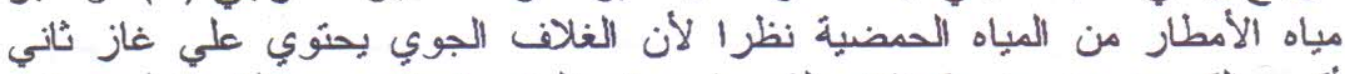

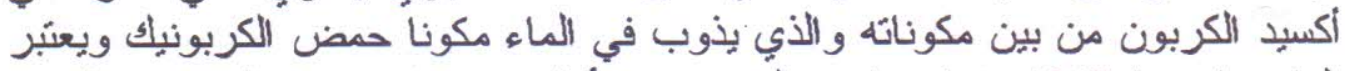

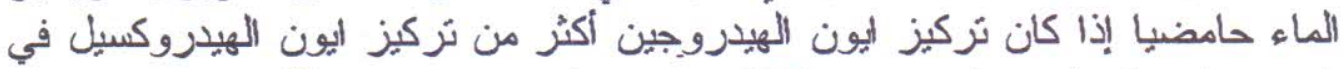

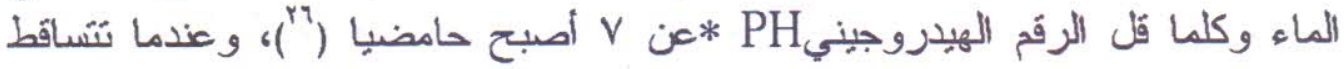

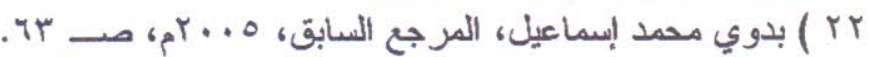
23) El-Derby, A., Two Examples of Egyptian alabaster Weathering Deterioration and damage from ancient Egyptian building and Islamic building in Egypt and some recommendations of preservation, journal of the general associate arab archaeology, arab council for graduates studies and scientific research, AGGSSR and supreme council of antiquities, 2009.

24) Montana, G.and Randazzo, L. ,The growth of " black crusts " on calcareous building stones in Palermo ( Sicily) afirst appraisal of anthropogenic and natural sulphur sources, Environ Geol. 56: 367 - 380, Published online 18 January 2008 , Springer - Verlag 2008 , P.378.

25) Prikryl ,R. \& Smith, B.J. , effect of long - term changes in air pollution and climate on the decay and blacking of European stone buildings, Building stone decay : from diagnosis to conservation, the geological society, London, 2007 , P 119.

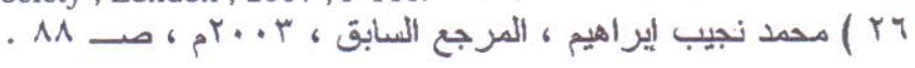




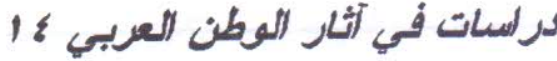

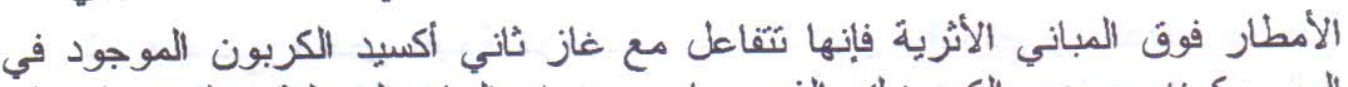

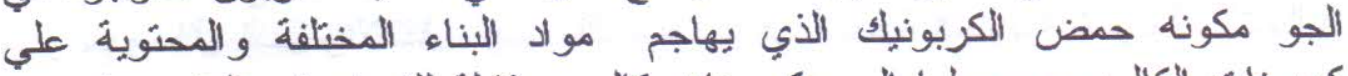

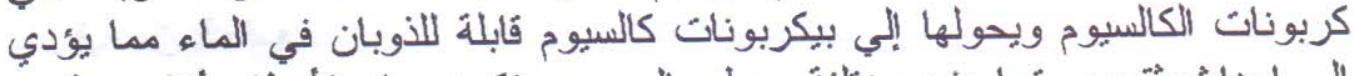

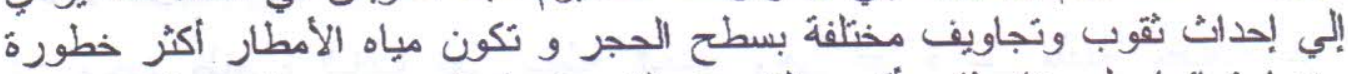

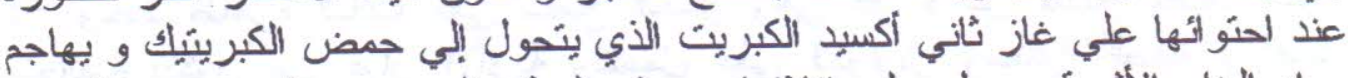

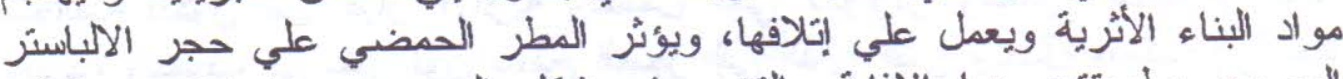

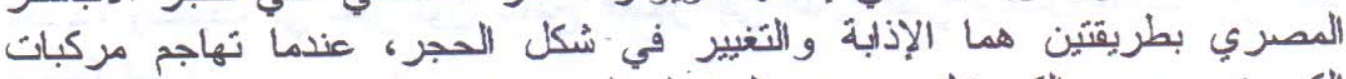

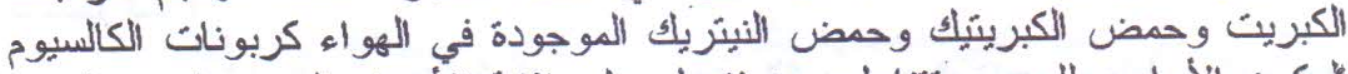

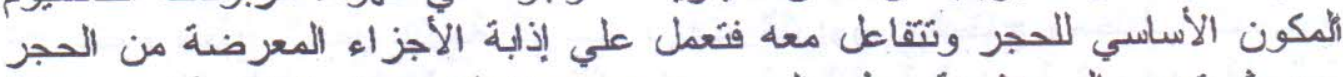

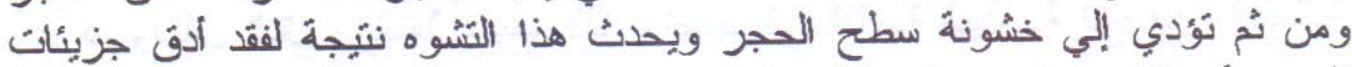

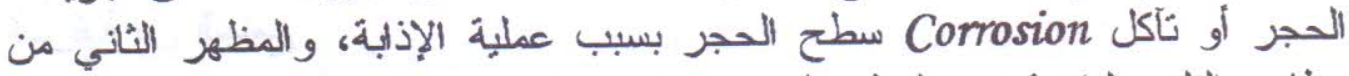

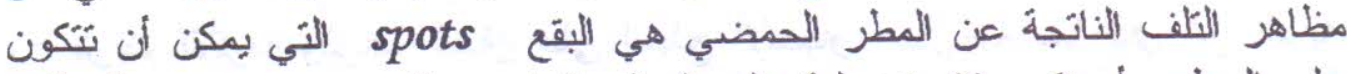

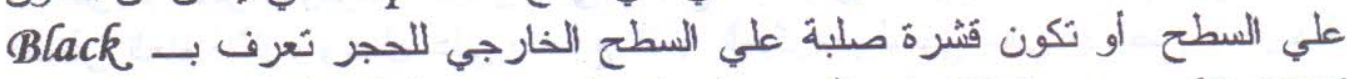
crust

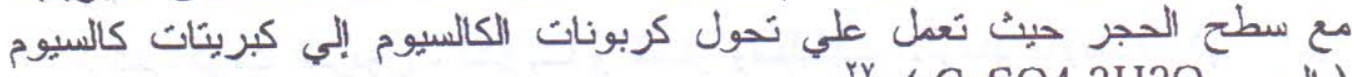

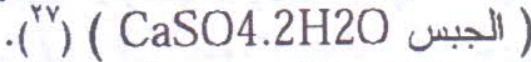

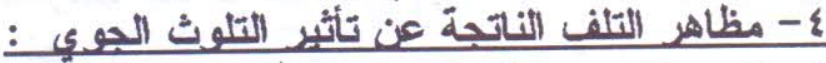

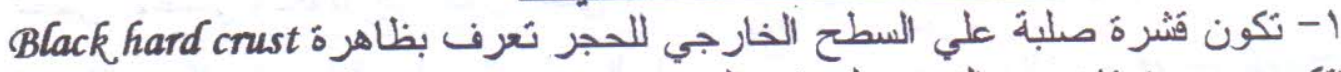

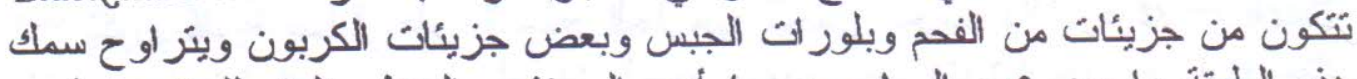

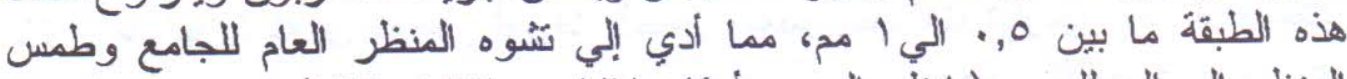

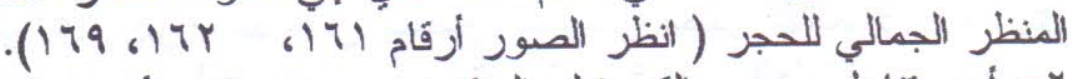

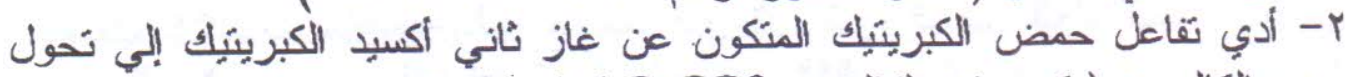

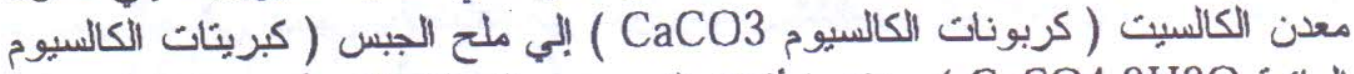

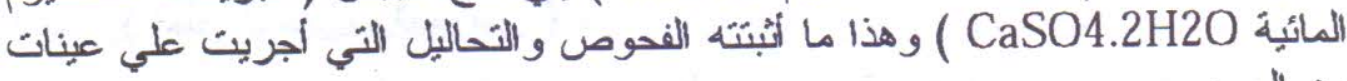

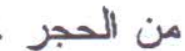

* ) يستخلم اصطلاح الرقم الهيدروجيني PH للتعبير عن حموضة المحاليل أومكوناتهـا ، والــرقم

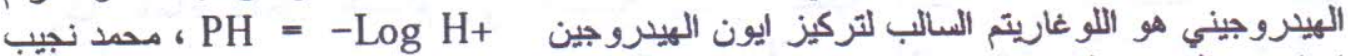

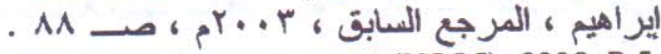
27) Elaine, M., Acid rain and nation's capital, science for a changing world (USGS), 2002, P.5. (http://pubs.usgs.gov/gip/acidrain/6.html) 


\section{درسات في آثار الموطن العربي ؛ 1}

r- تشويه سطح الحجر نتيجة لترسب ذرات الكربون والسناج ومخلفات المصانع

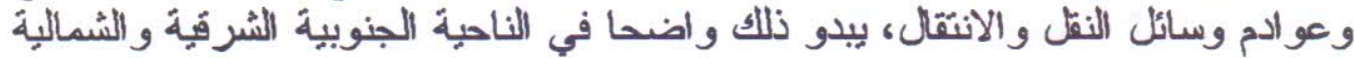

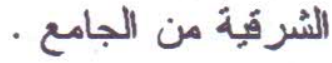

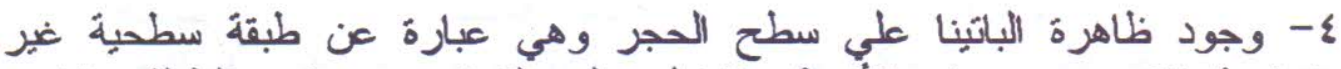

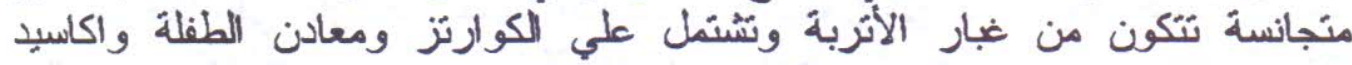
الحديد، وتتسبب في تغير لون سطح الحجر إلي اللون البني ويصل سمكها إلي عدة الطئ

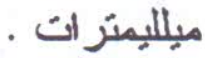

0- تشوه سطح الحجر نتيجة لترسب ذرات الكربون والسناج ومخلفات المصانع

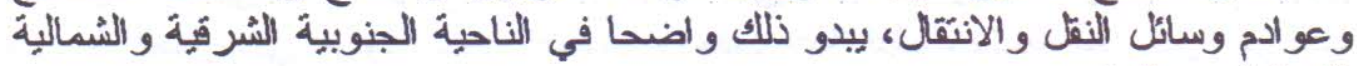

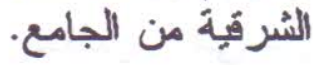

ج- تراكم الأتربة وذرات الغبار علي أسطح الأحجار الخارجية مما أدي إلي تشويه

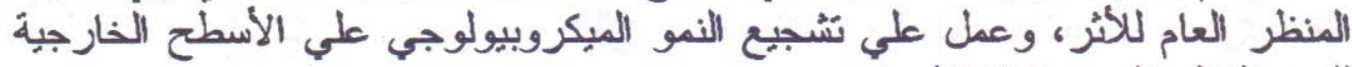

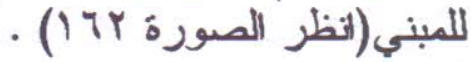

V- ترسب ذرات الكربون والكبريت و الغبار وسيليكات الالومنيا بالإضافة إلي اكاسبد

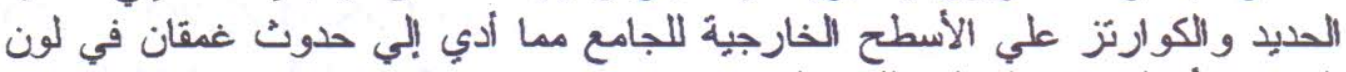

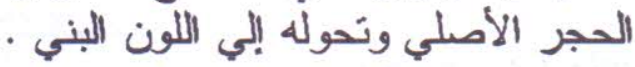

1- نكون قُرة صلبة طي السطح الخارجي للحجر تعرف بظاهرة

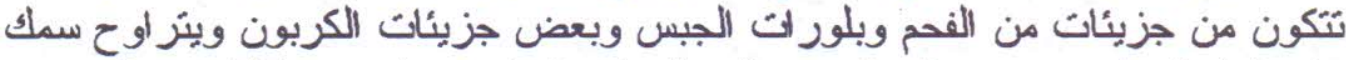

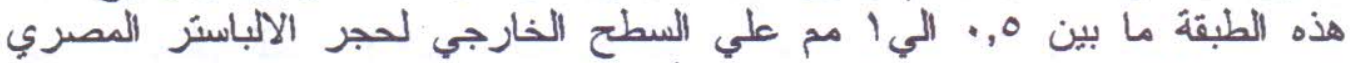

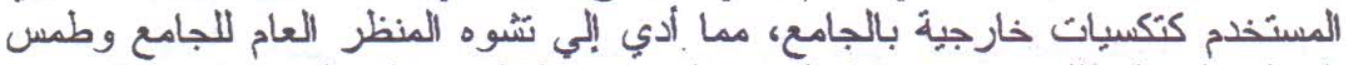

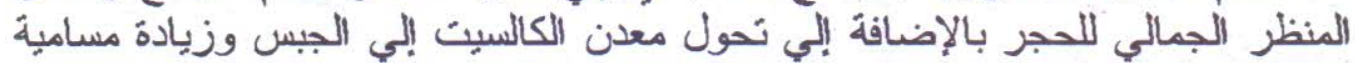
الحجر ( انظر التحاليل و الفحوص ) ) بالإنة

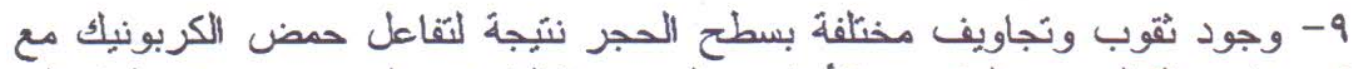

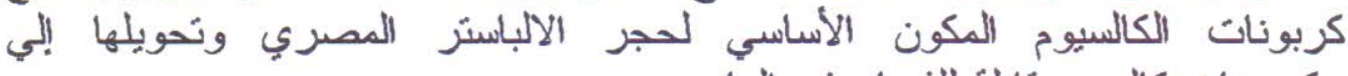
بيكربونات كالسيوم قابلة للذوبان في الماء.

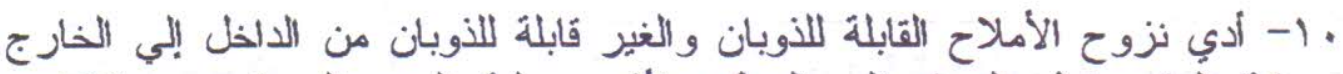

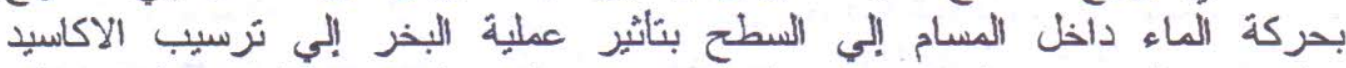

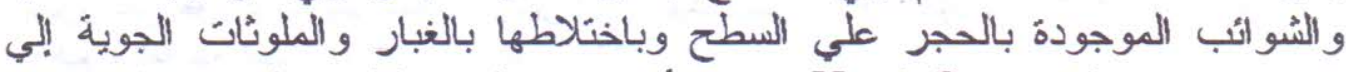

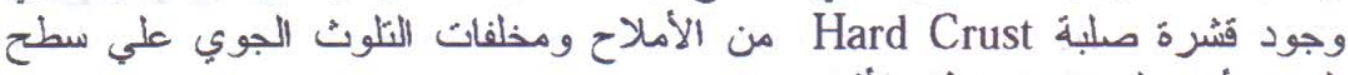
الحجر أدت إلب تشوه منظر الأثر. 


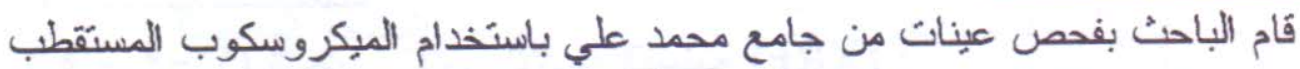

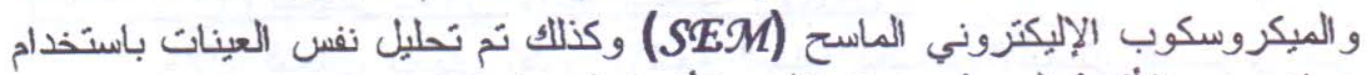
جهاز حيود الأشعة السينية وجهاز تفلور الأشعة السبنية .

$$
\text { : الفصواسة البتروحرافية }
$$

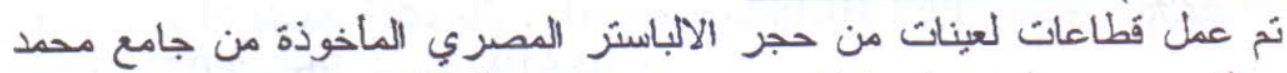

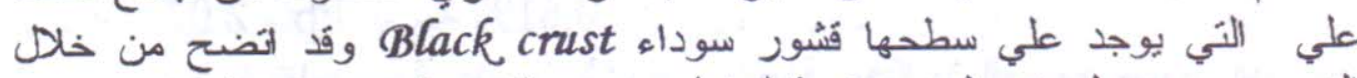

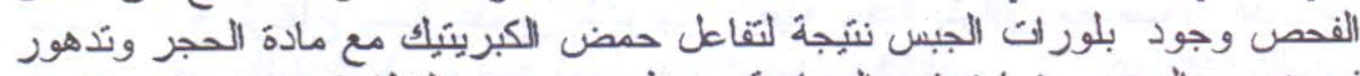

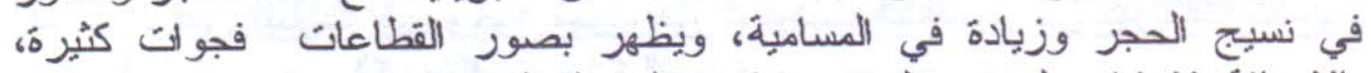

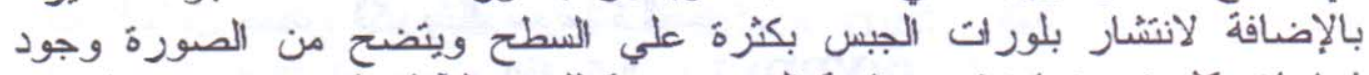

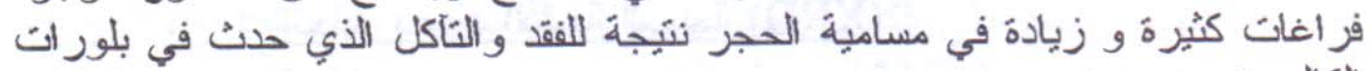

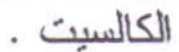

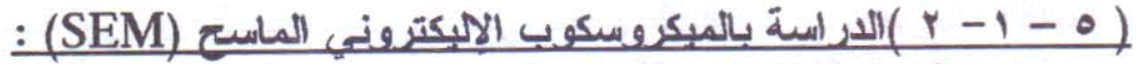

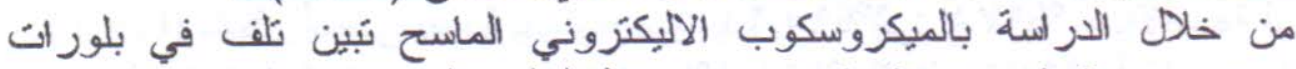

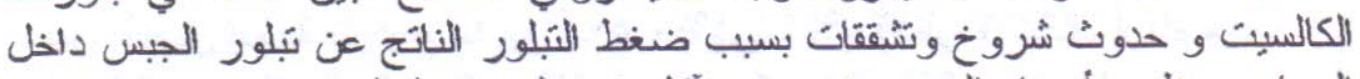

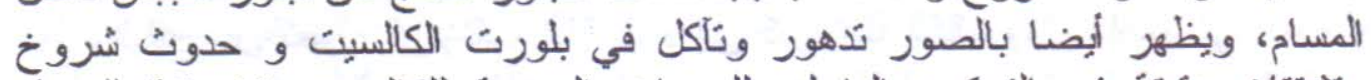

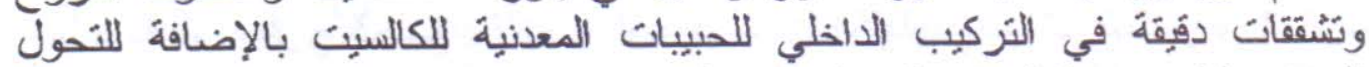

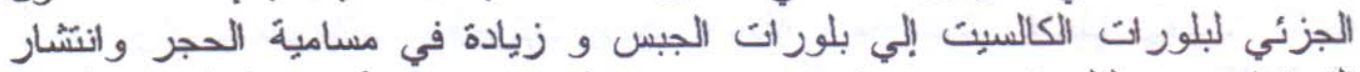

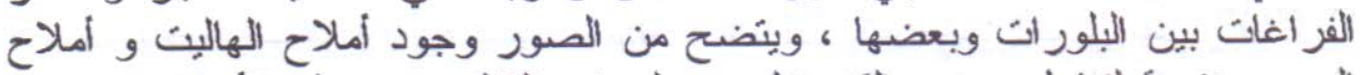

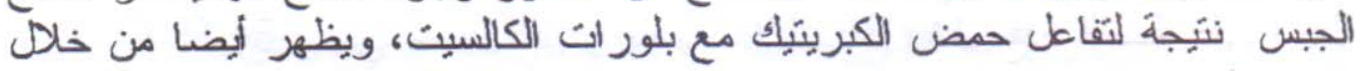

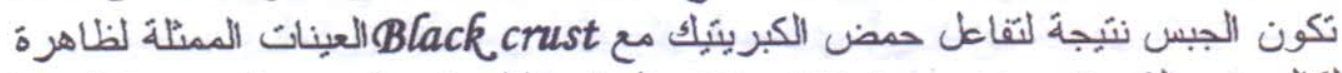

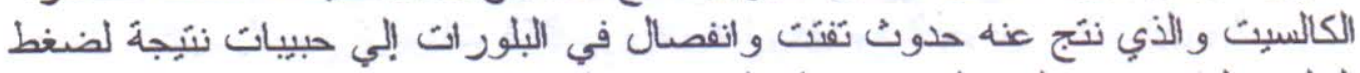

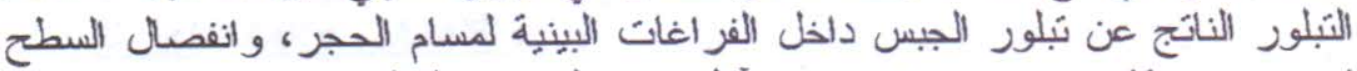

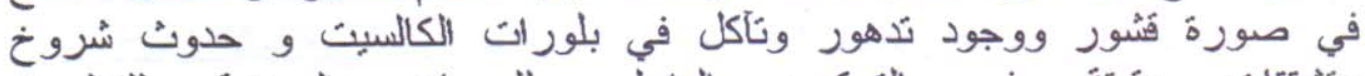

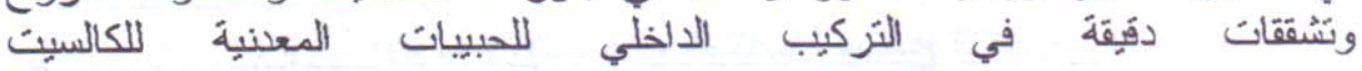
Micro cracks in internal structure 
درسات في آثار لالمطن العربي ؛

: التحاليل

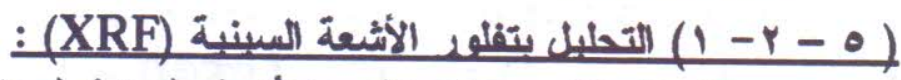

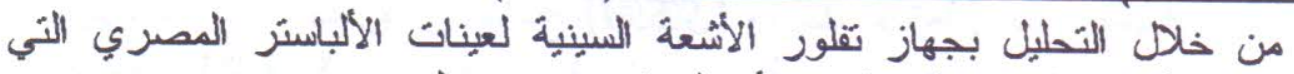

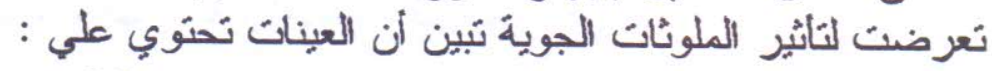

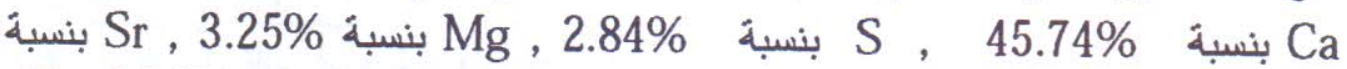

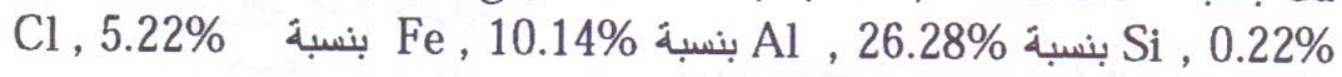

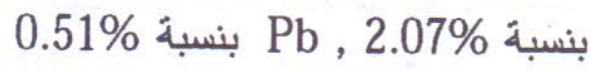

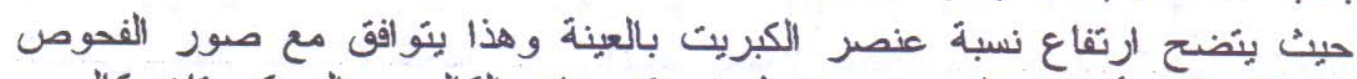

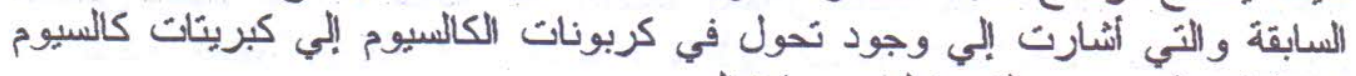

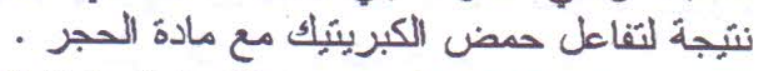

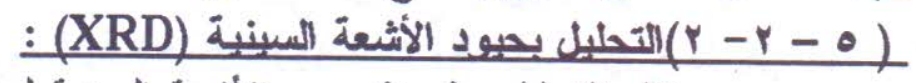

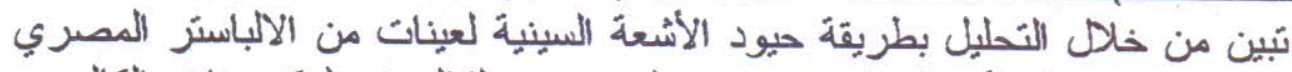

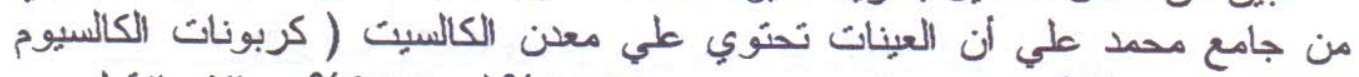

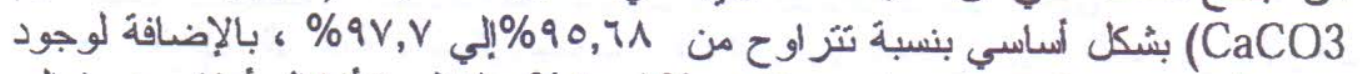

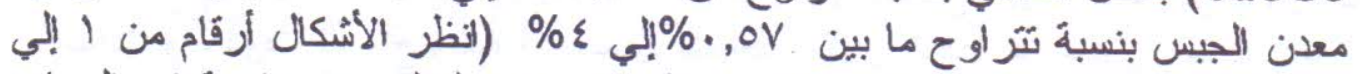

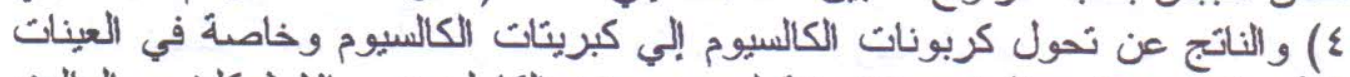

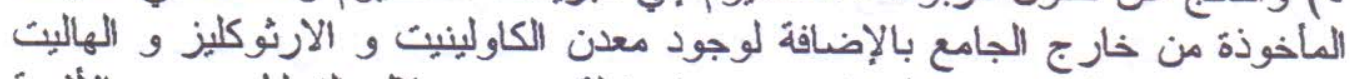

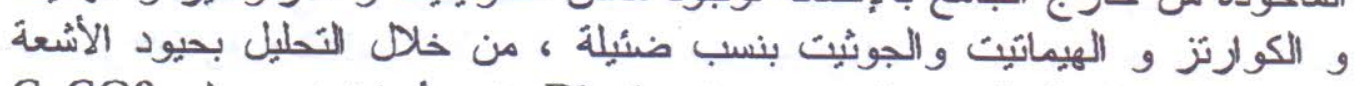

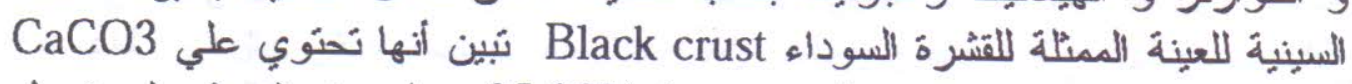
بنسبة 64.36\% وعلي معن الجبس بنسبة 35.36\% وندل هذه النسبة النسبة علي تحول

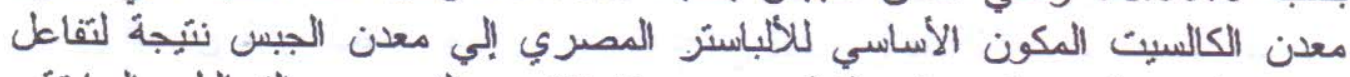

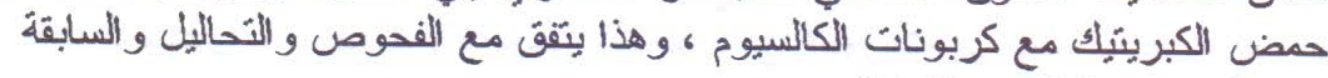
7- اقتراحات العلاجو الحفاظ : ) (1)

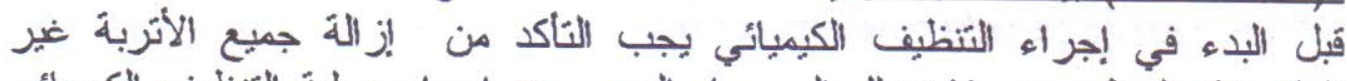

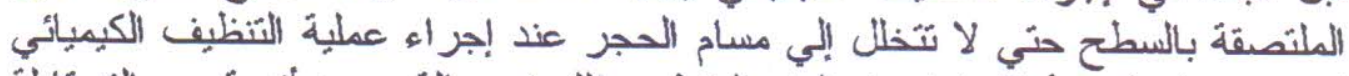

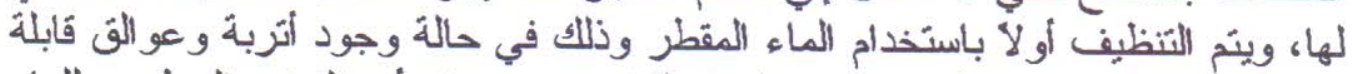

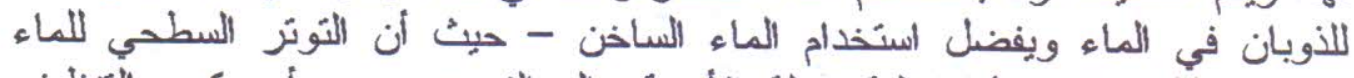

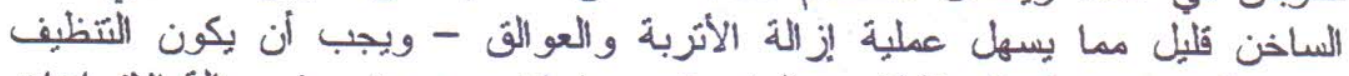

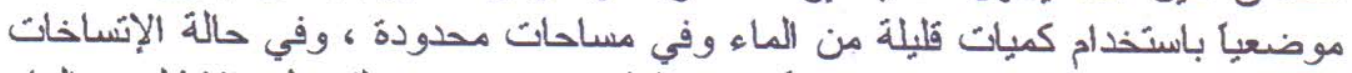
الملنصقة بسطح الحجر بِّتخدم أولا محلول مركب من الكحول الإيثلي والماء 


\section{دراسات في آثار الوطن العربي ؛ 1}

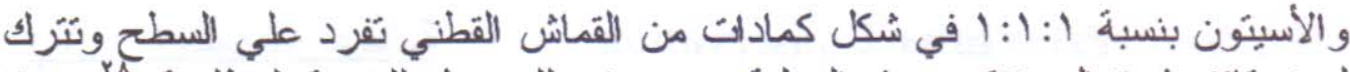

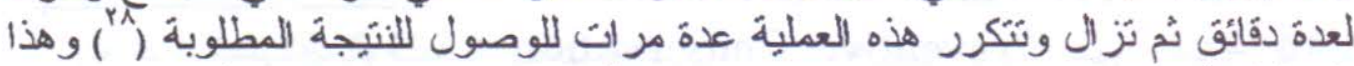

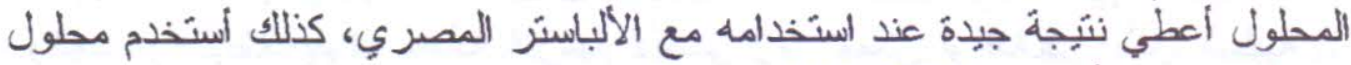

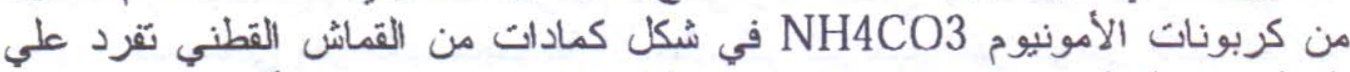

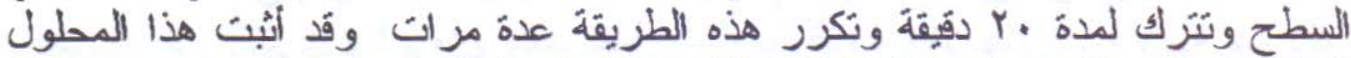

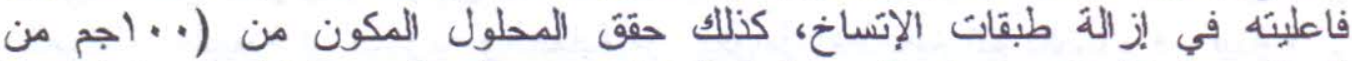

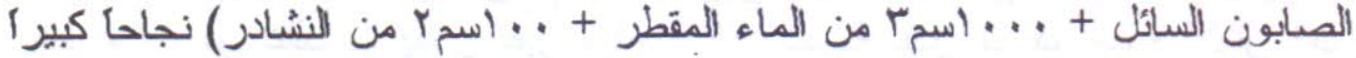

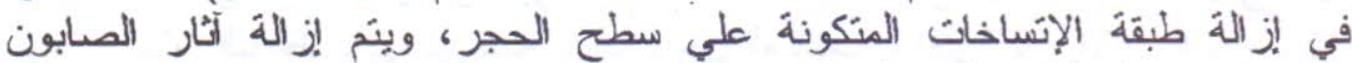

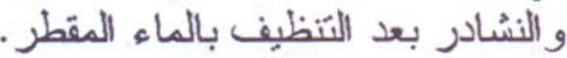
Black crust الموحودة علي سطح التكسيات : الستخدمت لإزالة طبقة

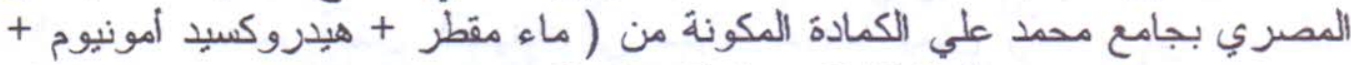

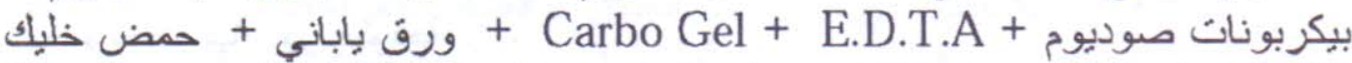
צ\% + مطهر فطري ) و و تعنبر هذه الكمادة من أفضل العجائن المستخدمة لإزالة

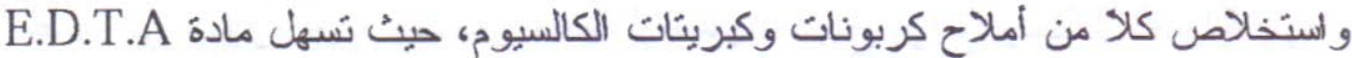

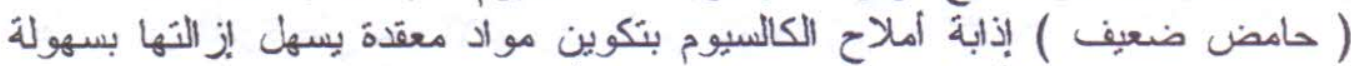

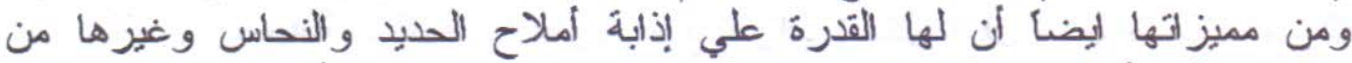

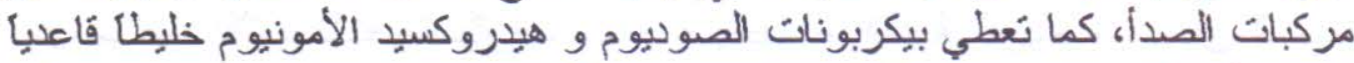

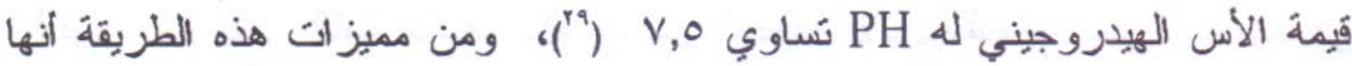

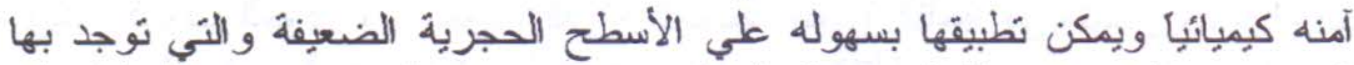

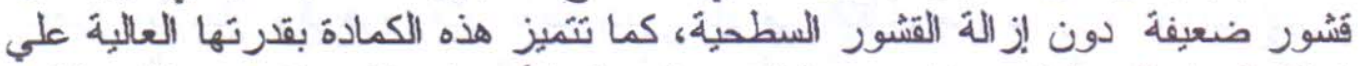

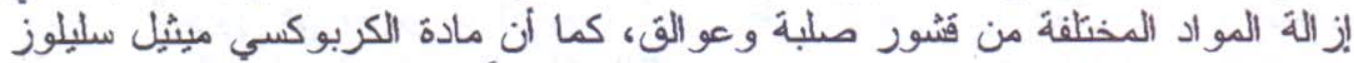

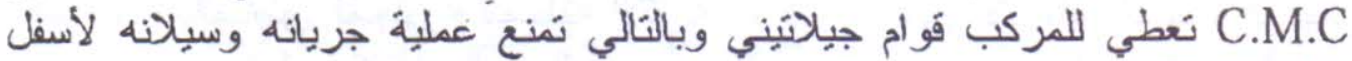

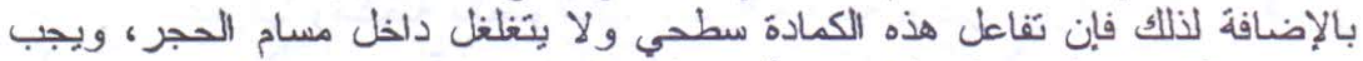

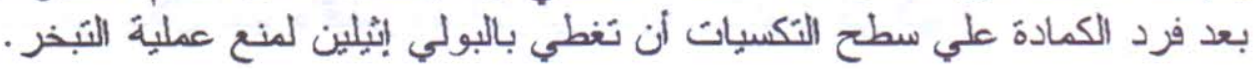

28) Larson, J., The conservation of stone sculpture in museums in conservation, in: Conservation of building and Decorative stone, Vol 2, London, 1990, P. 200.

29) Lazzarini.L, Tabasso.M.L, Op.Cit., 1986, P 135. 


\section{Preventive Conservation}

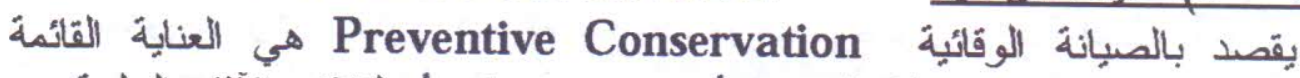

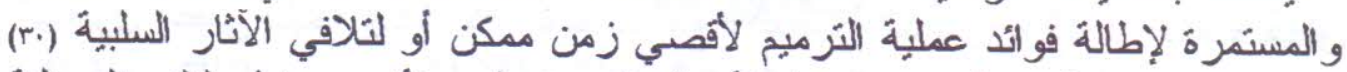

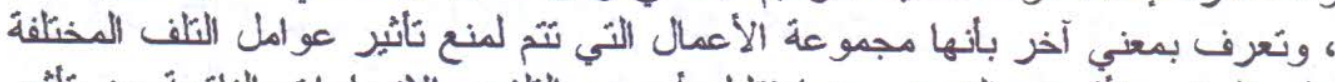

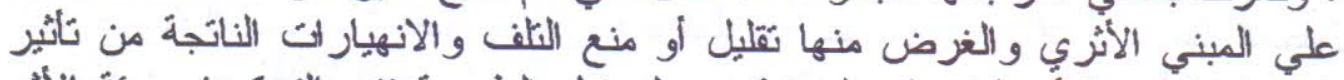

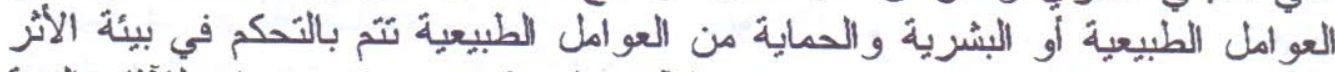

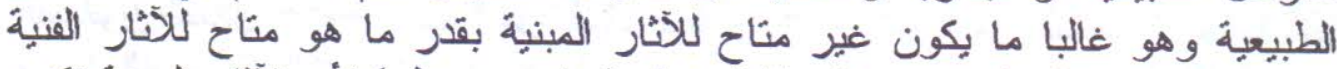

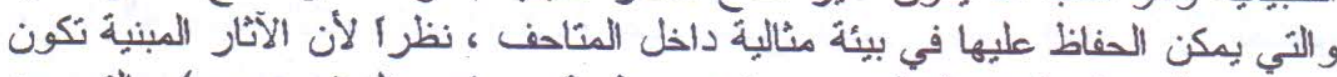

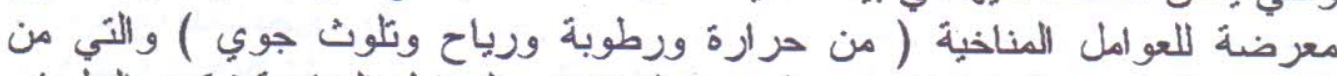

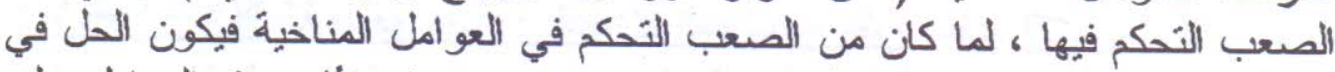

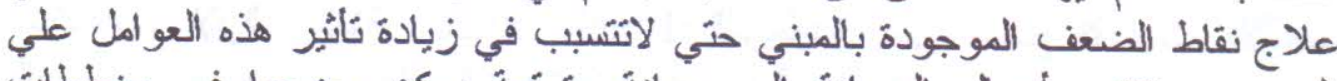

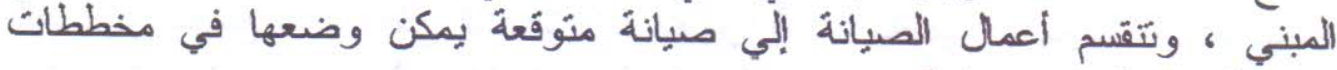

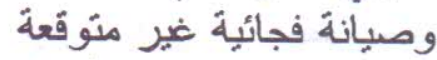

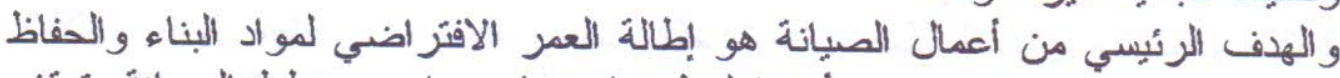

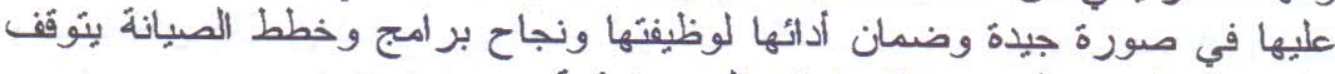

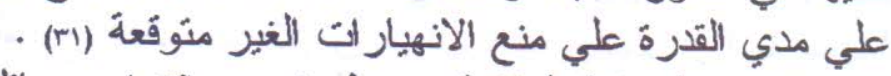

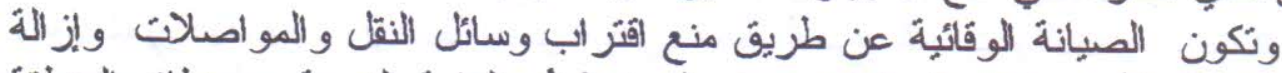

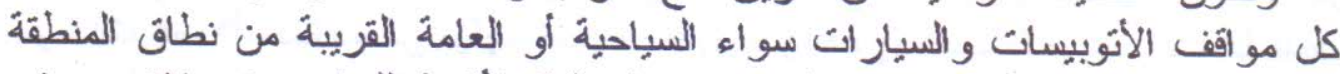

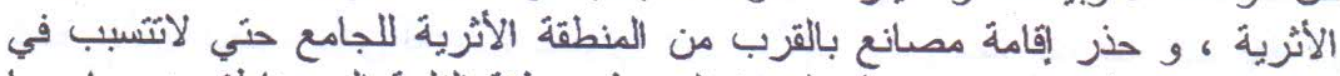

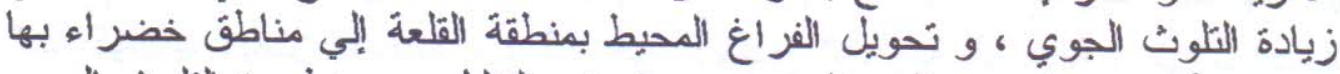

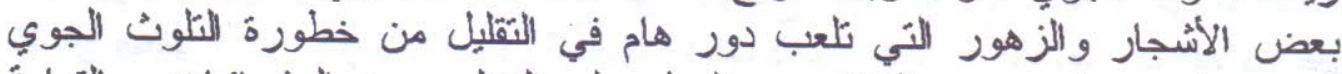

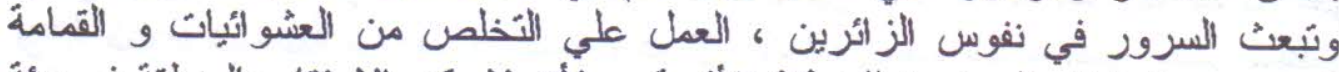

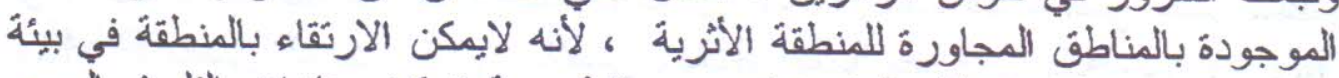

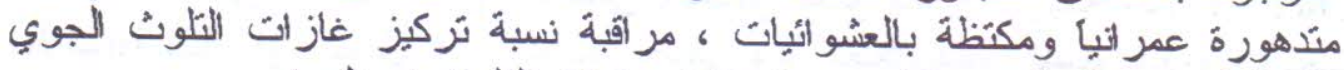

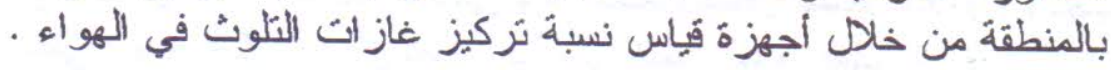

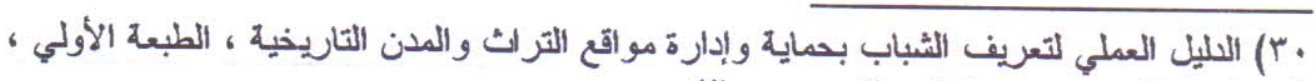

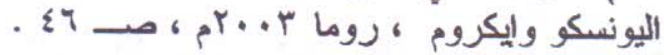

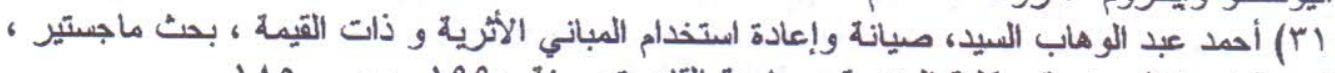

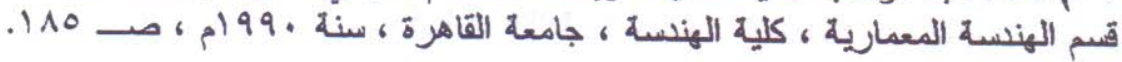




\section{درسات في أثار المطن العربي ؛ 1}

مناقثة النتائج و التوصـيـات

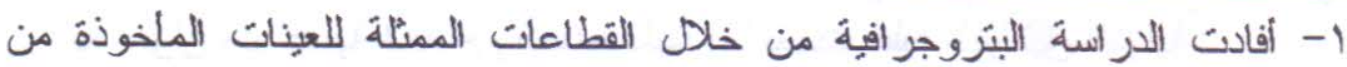

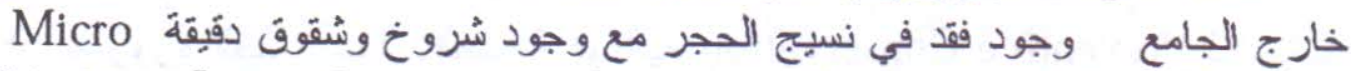

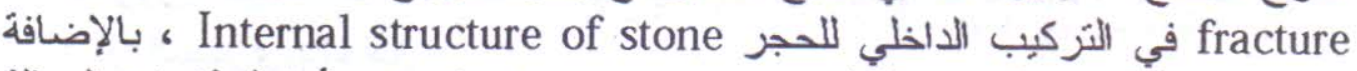
إلي وجود تآكل في بلورات الكالسيت مع وجود فجوات كبيزة ، أما القطاعات الممثلة

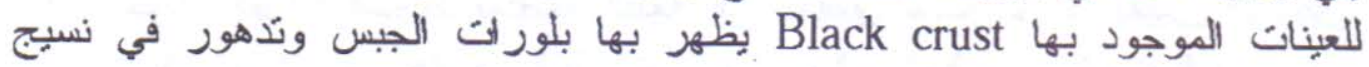

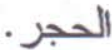

- أفادت الدراسة من خلا الفحص بالمبكروسكوب الاليكتروني الماسح (SEM)

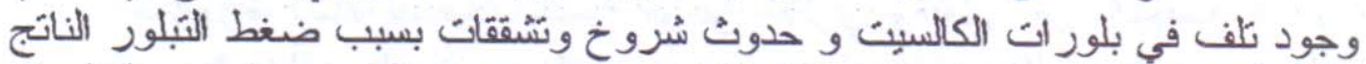

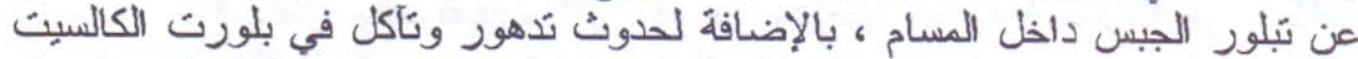

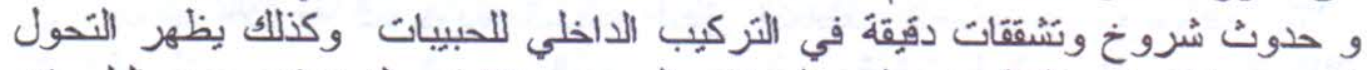

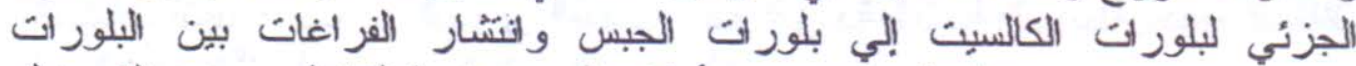

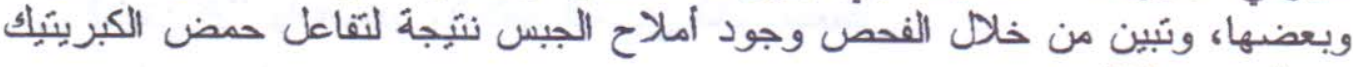

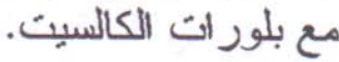

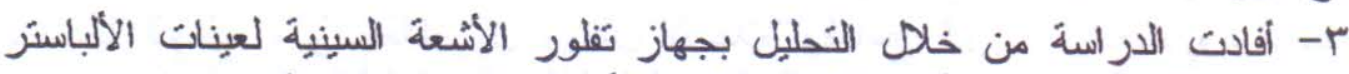

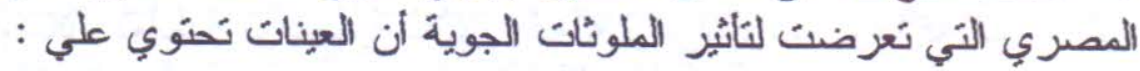

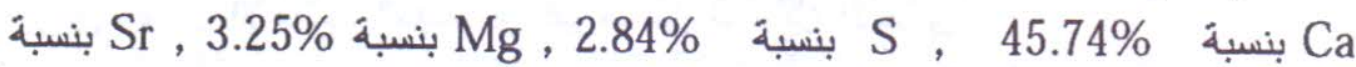
Cl , 5.22\% بنسبة Fe , بنسبة Pl , 26.28\% بنسة Si , 0.22\% بنسبة Pb , 2.07\% بنسبة 0.51\%

ع- أفادت الدراسة من خلا التحليل بحيود الأشعة السينية للعينة الممثلة للقشرة السوداء Black crust تبين أنها تحتوي علي

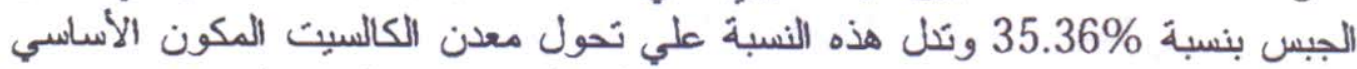

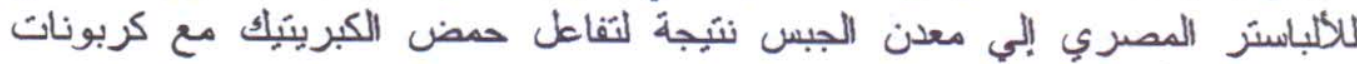

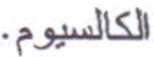

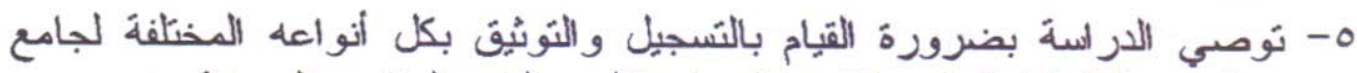

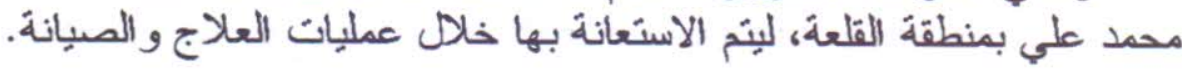

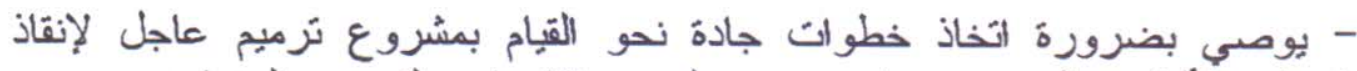
تكسيات الالاسبتر المصري بجامع محمد علي من الانهيار والتدمير و الضياع.

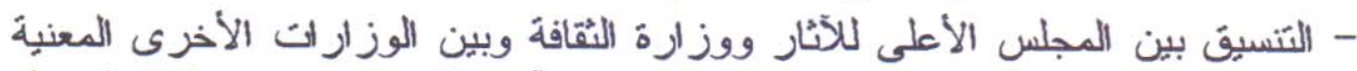

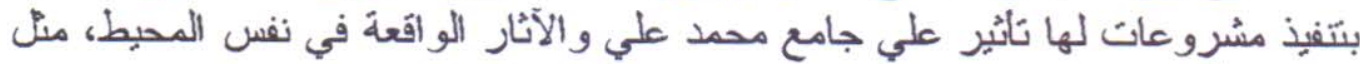
مشروع أبر اج القلعة. 


\section{درسات في آثار الوطن العربي \& 1}

1- يوصي بضرورة استخدام التقنيات العلمبة الحدينة في مجال ترميم وصبيانة المباني

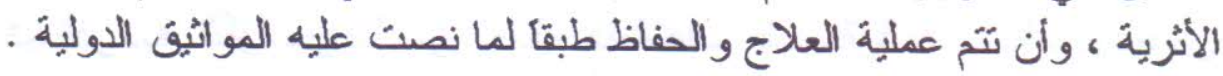

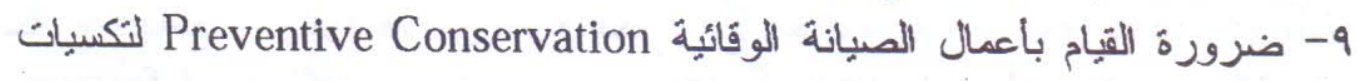

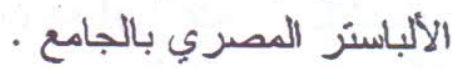

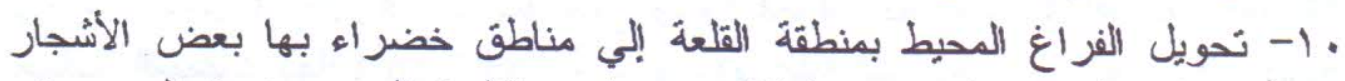

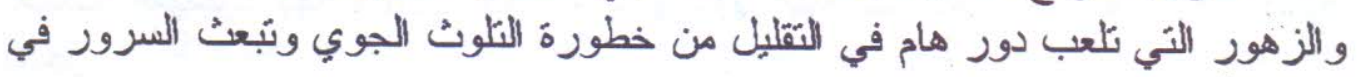

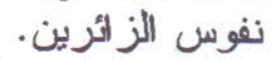

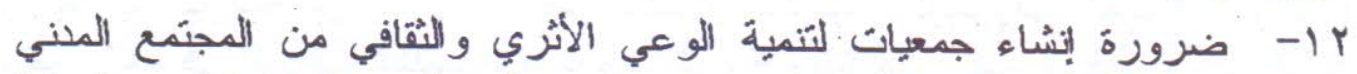

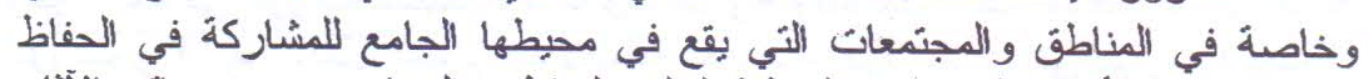

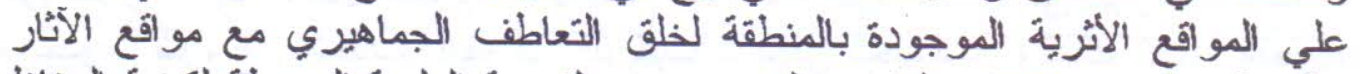

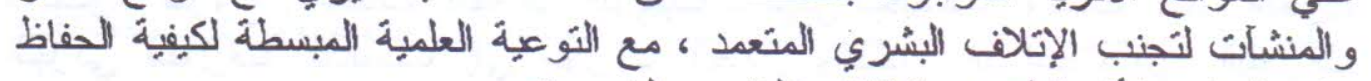

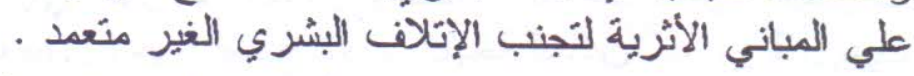

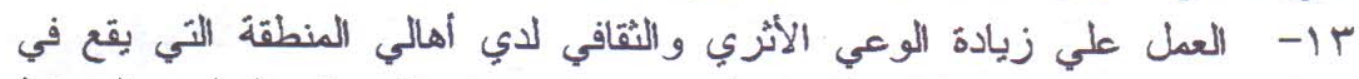

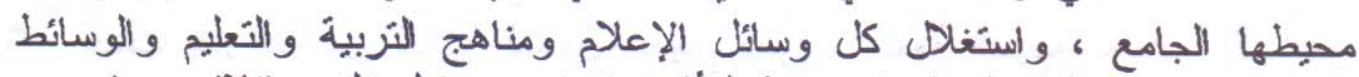

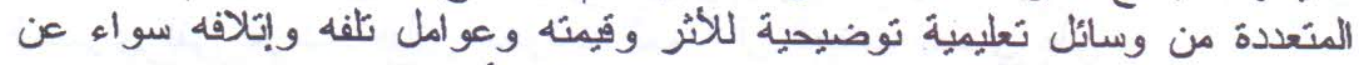

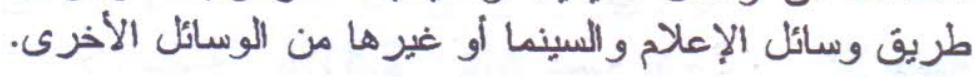




\section{درسات في آثار الموطن العربي ؛}

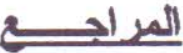

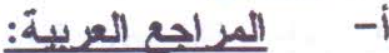

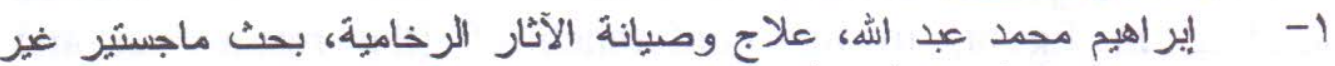

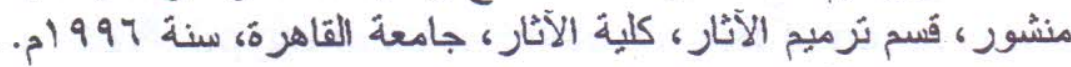

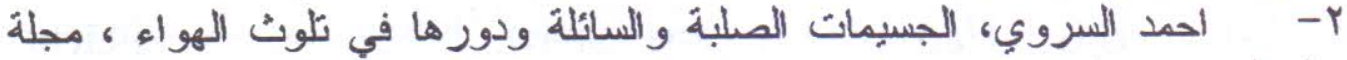

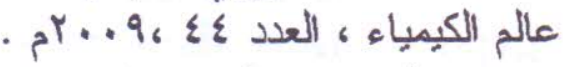

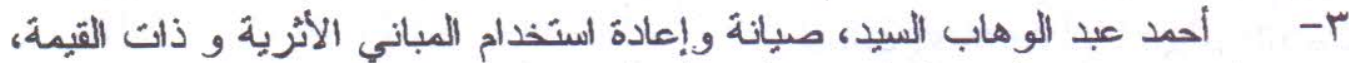

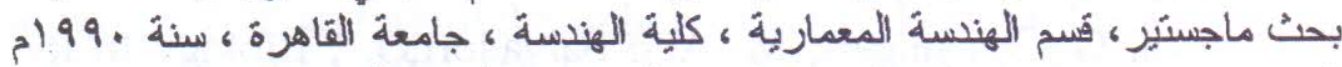

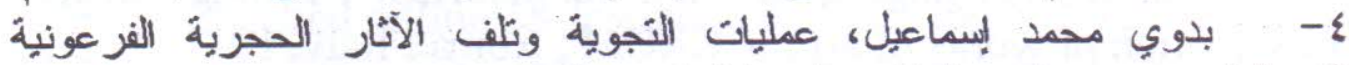

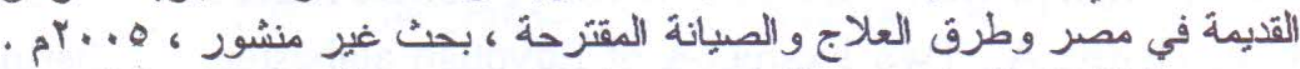

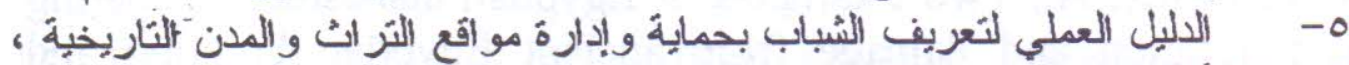

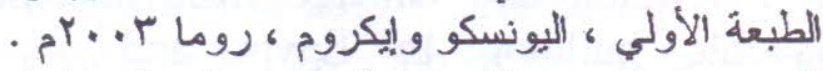

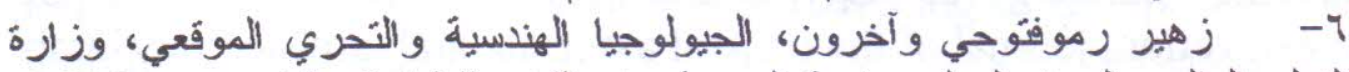

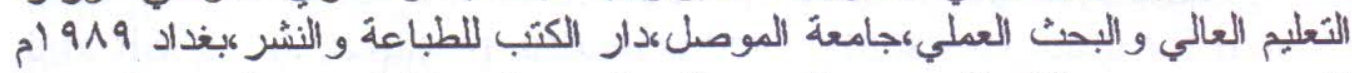

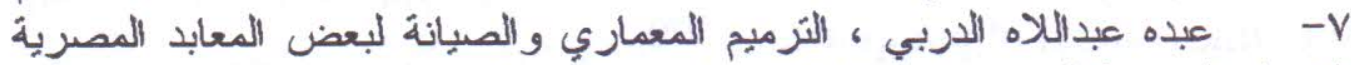

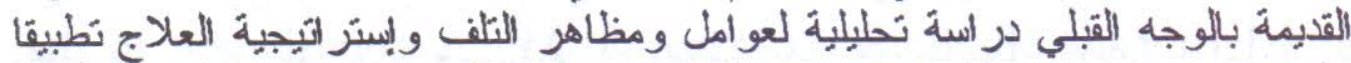

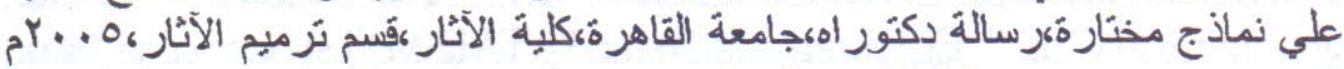

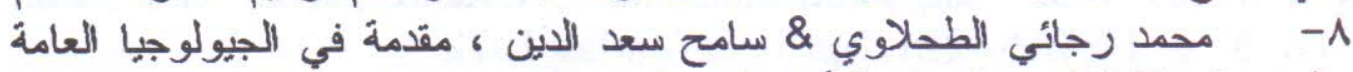

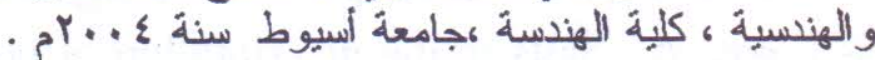

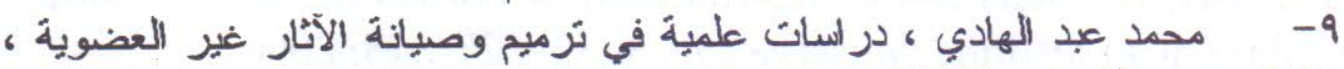

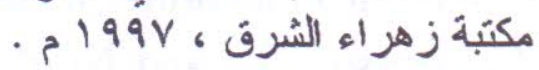
• 1- محمد نجيب إير اهيخ ، التلوث البيئي ودور الكائنات الدقيقة إيجابا وسلبا ،دار

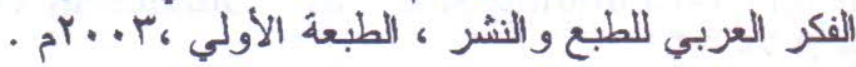

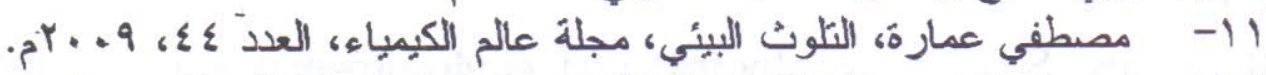

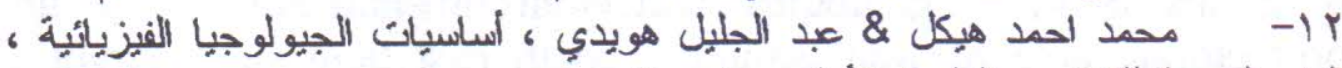

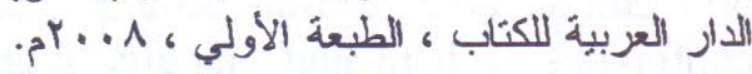

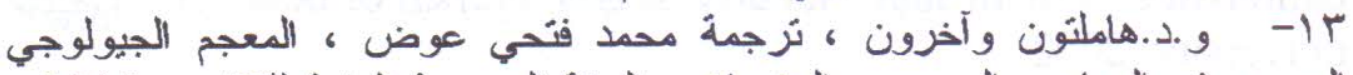

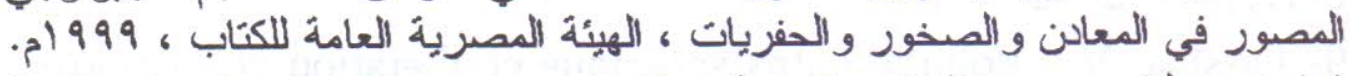

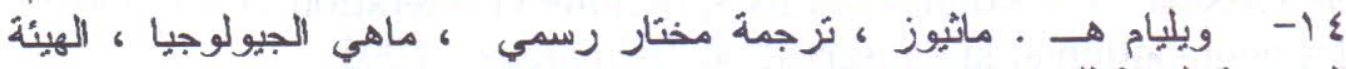

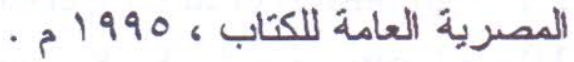




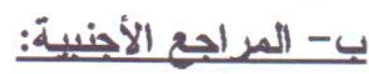

1- Abd Elhady, M., Ground water and the deterioration of Islamic building in Egypt, in the conference of (the restoration and conservation of Islamic monuments in Egypt), AUC, 1995.

2- Aston, B.G., Harrell, J.A. and Shaw, I., Stone, in, ancient Egyptian materials and technology, Nicholson.T \& Shaw, I., Cambridge University, 2000.

3- Caneva, G., Pia nugari, M. And Salvadori,O., Biology in the conservation of works of art, ICCROM , Roma , Italy, 1991 .

4- El-Derby, A., Two Examples of Egyptian alabaster Weathering Deterioration and damage from ancient Egyptian building and Islamic building in Egypt and some recommendations of preservation, journal of the general associate arab archaeology, arab council for graduates studies and scientific research, AGGSSR and supreme council of antiquities, 2009.

5- E1.Hinnawi, E. E. \& Loukina, S. M., A contribution to the geochemistry of " Egyptian alabaster ", TMPM Tsehermaks Min. Petr. Mitt. 17, 215--221, Springer-Verlag 1972.

6- Elena, A., Salts in the deterioration of porous materials, journal of American institute conservation, V 39: 327-343, 2000.

7- Ericsson, T., and Nord, A, G., Chemical analysis of thin black layers on building stone in " Studies in conservation " 38, 1993, P.P.25-35.

8- Ewais, S.G., ., geological and environmental studies on the protectorate area of wadi sannur , south east beni suef ,Egypt , conference of beni suef, faculty of arts, branch of beni suef, Cairo university, 2002

9- Fassina, V., Pollution atmospherique et alteration de la pierre , La degradation et la conservation de la pierre , 1991.

10- Klemm, D. D \& Klemm. R, The building stones of ancient Egypt - a gift of its geology, journal of African earth science 33, El Sevier, 2001. 


\section{درسات في أثار المطن العربي ؛ 1}

11- Larson, J., The conservation of stone sculpture in museums in conservation, in: Conservation of building and Decorative stone, Vol 2, London, 1990, P. 200.

12- Lazzarini.L, Tabasso.M.L, IL Restauro Della Pietra, Casa Editrice Dott. Antonio Milani, 1986.

13- Montana, G.and Randazzo, L. ,The growth of " black crusts " on calcareous building stones in Palermo ( Sicily) afirst appraisal of anthropogenic and natural sulphur sources, Environ Geol. 56: 367 - 380 , Published online 18 January 2008, Springer - Verlag 2008. 14-Monica, T.P., Decorative Stone, Thames \& Hudson Ltd, London, 2007

15 - Prikryl, R. \& Smith, B.J. , effect of long - term changes in air pollution and climate on the decay and blacking of European stone buildings, Building stone decay : from diagnosis to conservation, the geological society, London, 2007.

16- Rovnanikova ,P., environmental pollution effects on other building material ,in, environmental deterioration of materials , Moncmanova, A., Southampton , Boston, 2007.

17- Soliman,N.F., Investigation of an Egyptian alabaster ore by measuring its natural radioactivity and by NAA using K0 standardization and comparator methods, journal of nuclear and radiation physics, Vol.1, No.1, 2006, P.32

18- Sivertsen, B., A study of air pollutants during episodes, ICEHM, Egypt , Page 345 - 361, Cairo University, September 2000.

19- Yilmaz and et.al. , Protection of marble surfaces by using biodegradable polymers as coating agent, Progress in organic coating 66, 213 - 220, www.elsevier.com, 2009. 


\section{دراسات في آثار الوطن العربي ؛ 1}

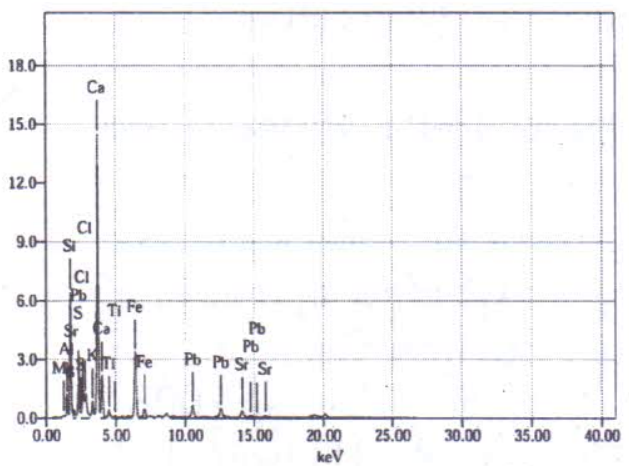

شكل رقم (Y) يبين نمط تفلور الأشعة السينية

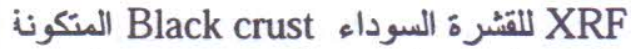
علي الالباستر المصري( جامع محمد علي من المنئ الخارج ( المعار)

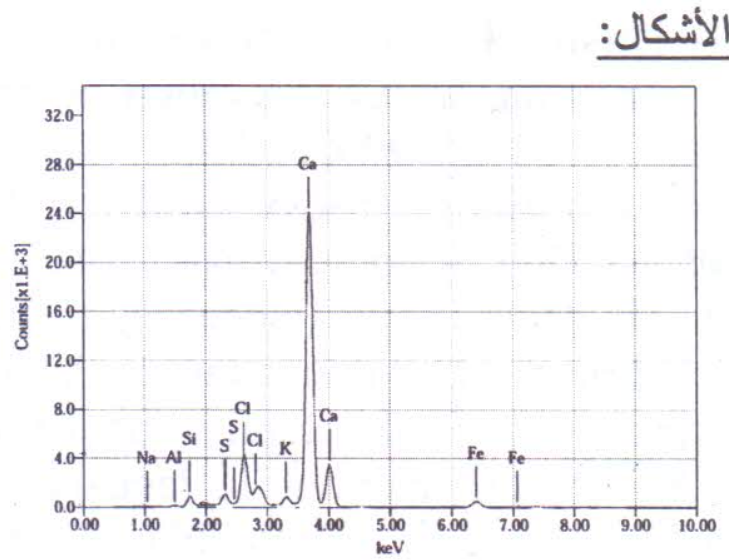

شكل رقم (1) يبين نمط تفلور الأشعة السينية

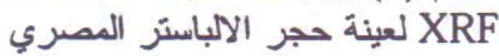
( جامع محمد علي من الخارج ) ل

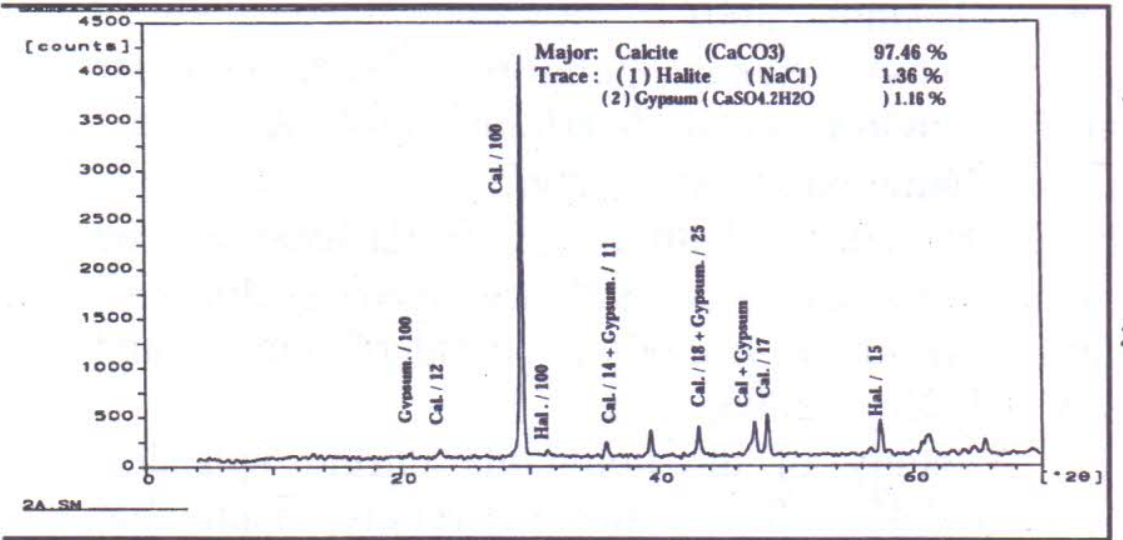

شكل رقم (r) يوضح نمط حيود الاشعة السينية ل لعينة من XRD

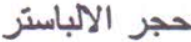
(الو اجهة الجنوبية

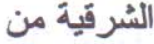

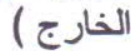

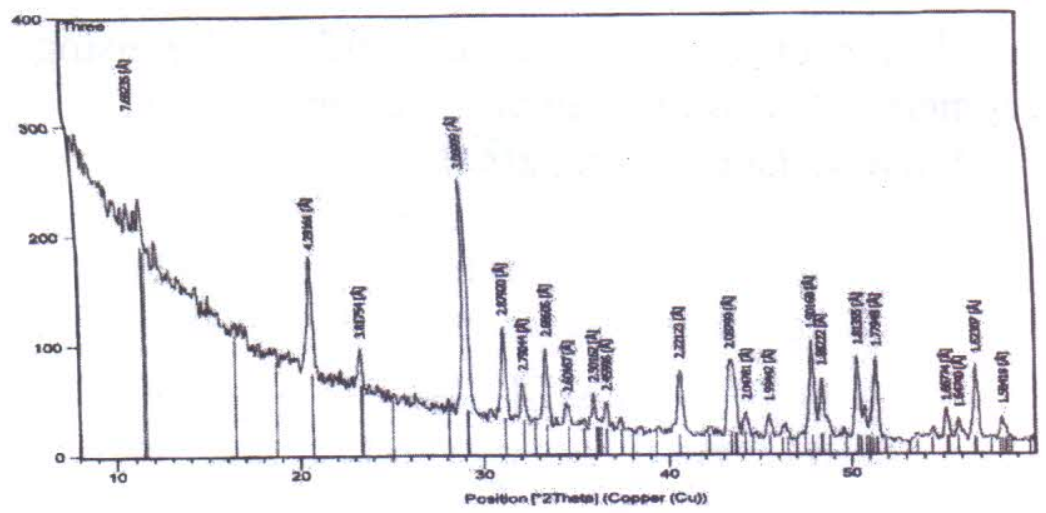

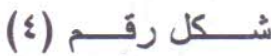
يبين نمــط حبـودود

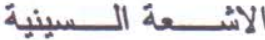
لعينة مـن الأن XRD

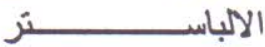

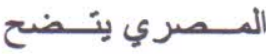

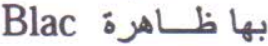
( ) Crust محمد علـي مسن جـن

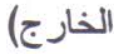




\section{دراسات في أثار الوطن العربي \&}
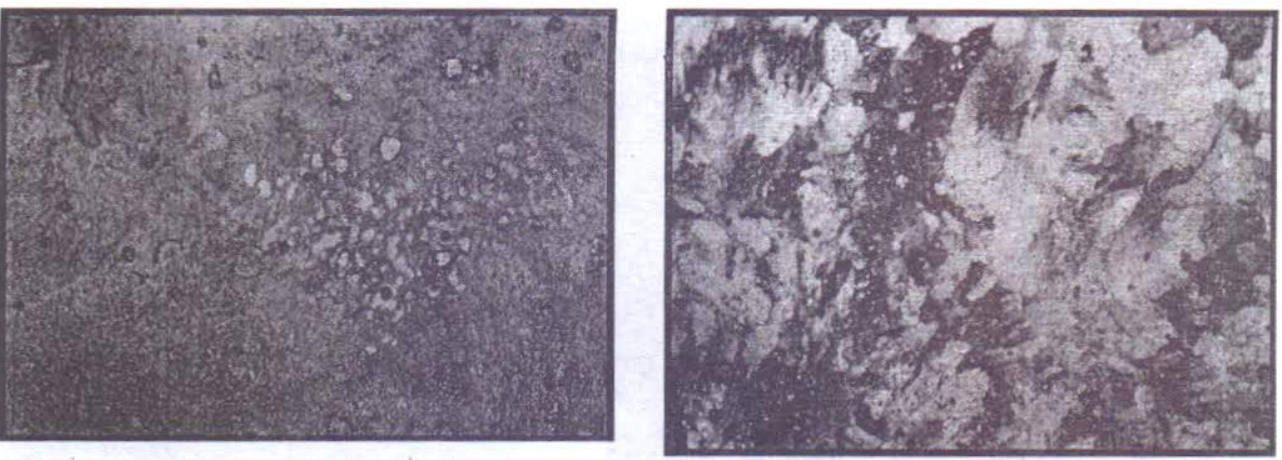

صورة رقم (r) تبين عينة لقط البـاع مــن

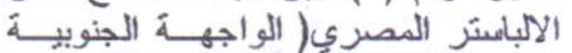

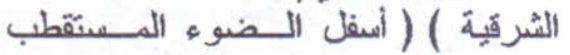

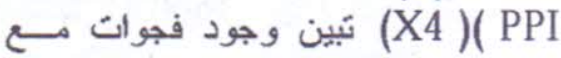

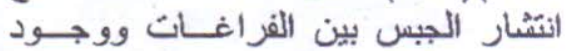

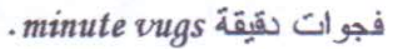

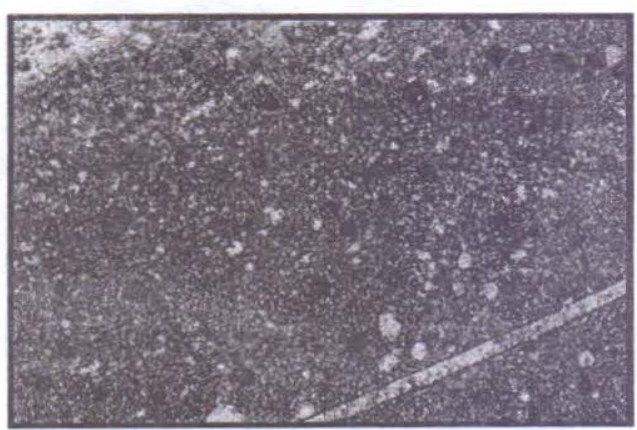

صورة رقم (ع) تبين عينة لقطاع من الالبانسـنز

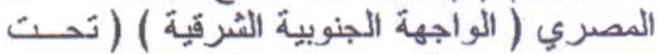

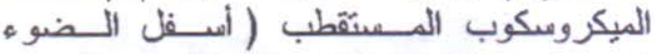

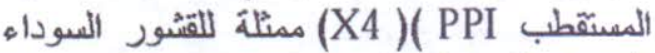
التي تغطي سطح الحجر Black crust ويظهر

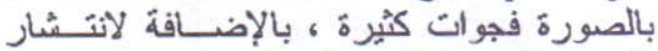

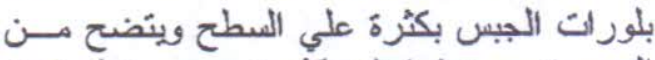

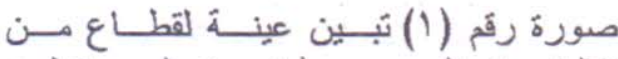

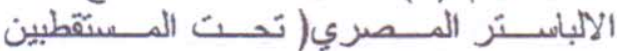

(C.N المتعامدين

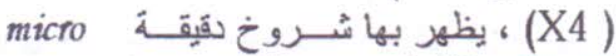
fissures فجوات ، ، كما يظهز بالقطاع بعض بلورئ التورات

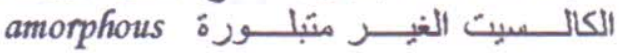
carfonates

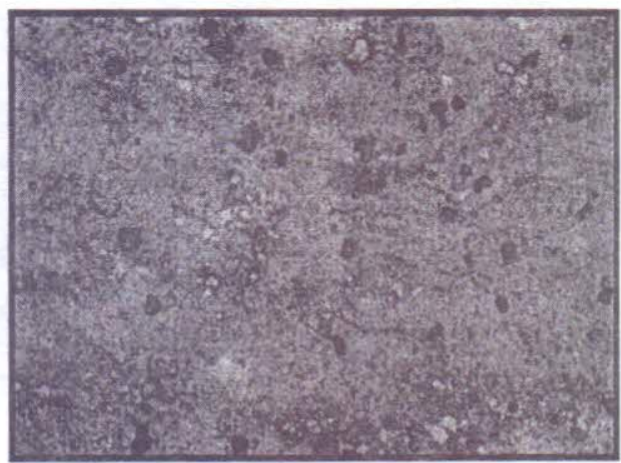

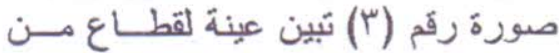

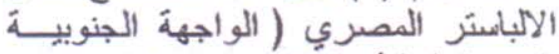

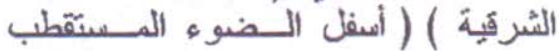
(X4) ( PPI انتشار الفجوات والقر اغات بنسيج الحجر تئر

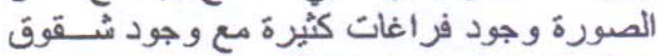

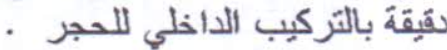


دراسات في آثار الموطن العربي ؛ 1

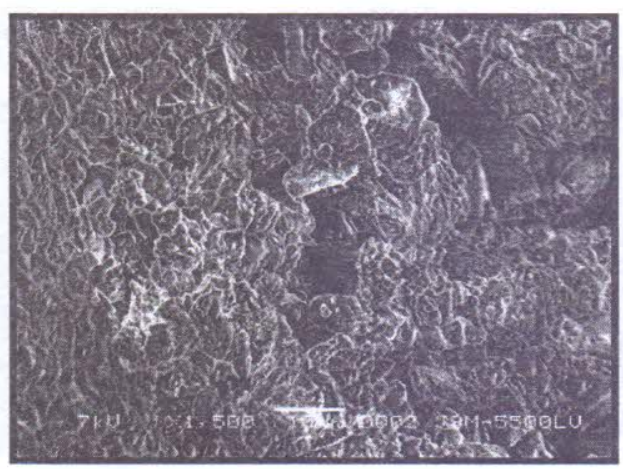

صورة رقم (؟) لعينة الالباستر المـصري

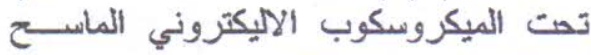
1500X تنبين تدهور وتآكل في بلورات الكالسيت و زيادة في مستسامية تور وناكية

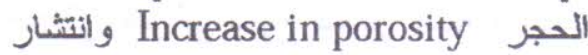
الفر اغات بين البلورات وبعضهها.

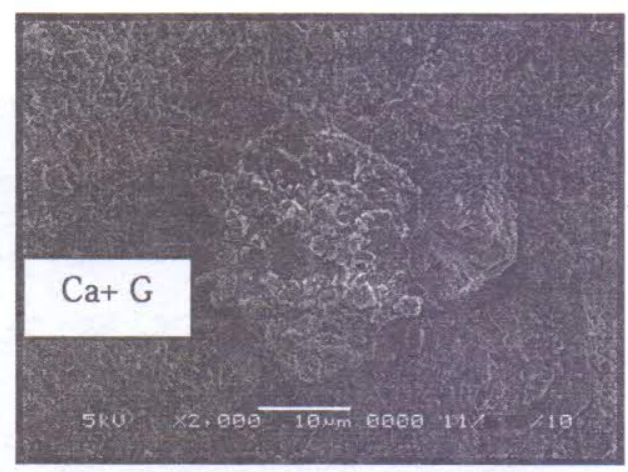

صورة رقم (1) لعينة الالباستر المصري

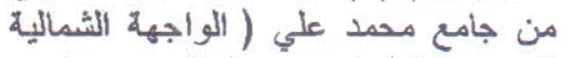

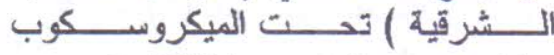

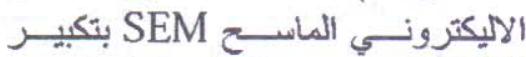

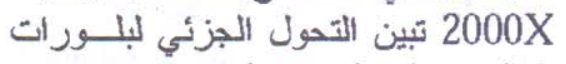
الكالسيت إلبي بلورات الجبس الجزئ

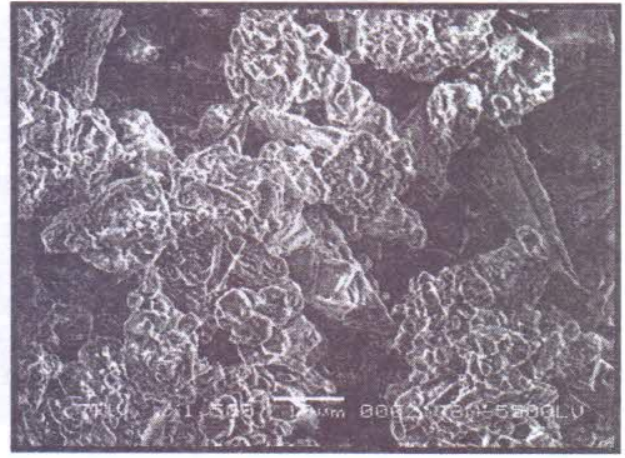

صورة رقم (0) لعينة الالباستر المــصري

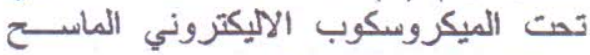
1500X بتين تدهور وتشوه

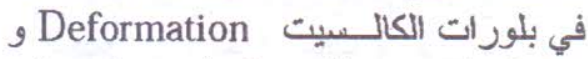

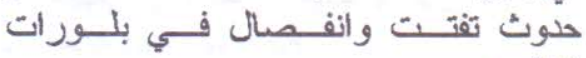
الكالسيت.

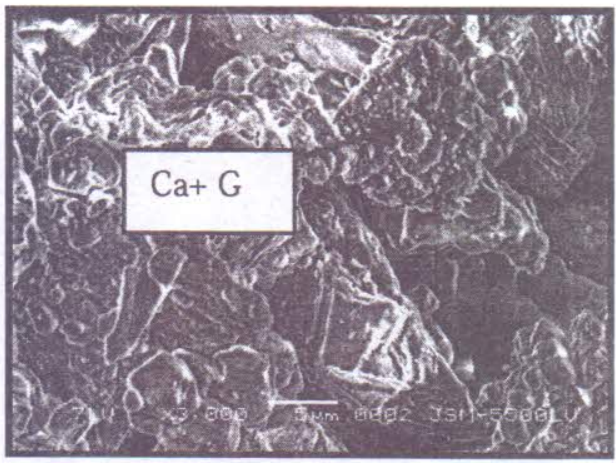

صورة رقم (V) لعينه الالباستر المـصري

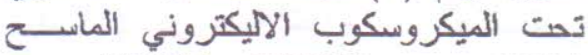
3000X , 5000X بتكبيـــــ SEM تدهور وتآكل في بلورات الكالسيت وانتشار

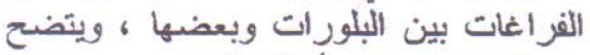
من الصورة وجود أملاح الجبس. 


\section{لدرلسات في آثار اللوطن العربي ؛ 1}

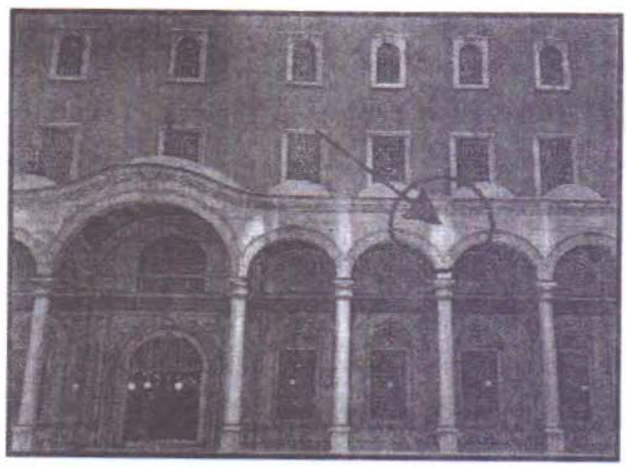

صورة رقم ( 9) تبين تأثير المطر الحمضي علي

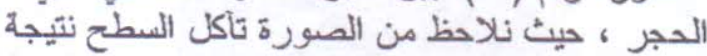

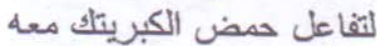
(الو اجهة الثمالية الغربية من الخارج ) -

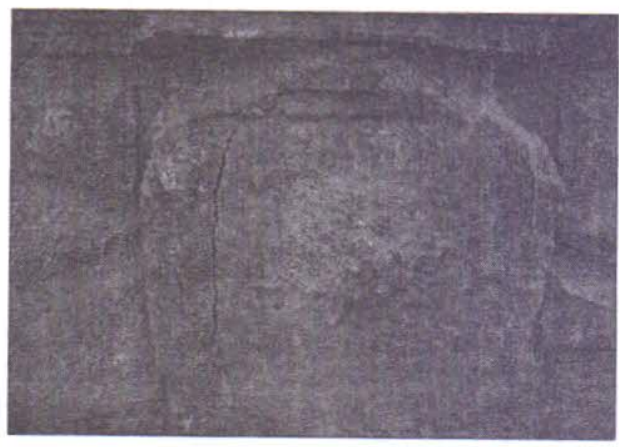

صورة رقم ( • 1) تبين القشرة السوداء Black

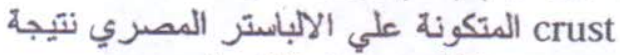
لتأثير عوأمل التلف الجئ الجوي

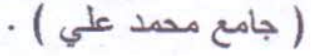

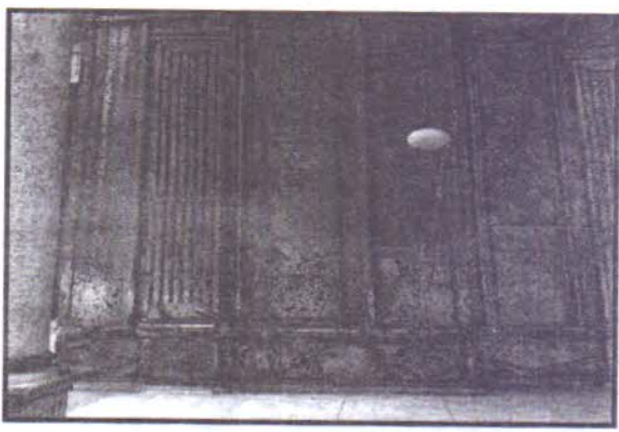

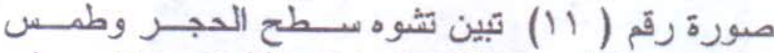

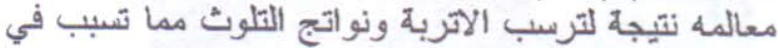

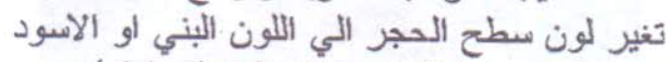

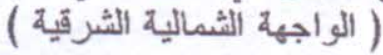

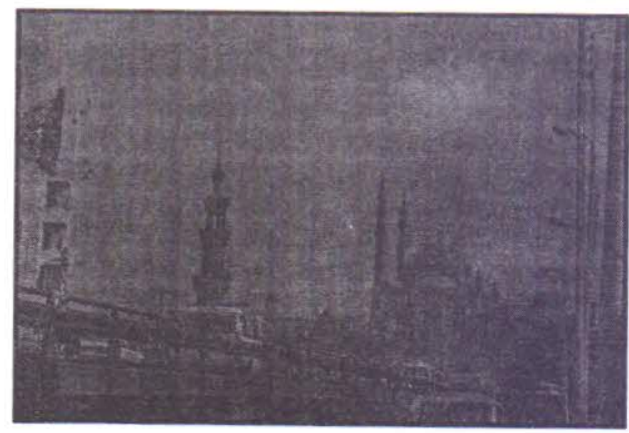

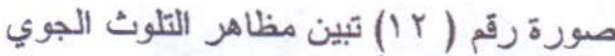

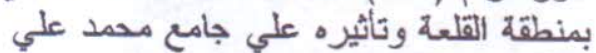


لدراسات في آثار المطن العربي ؛

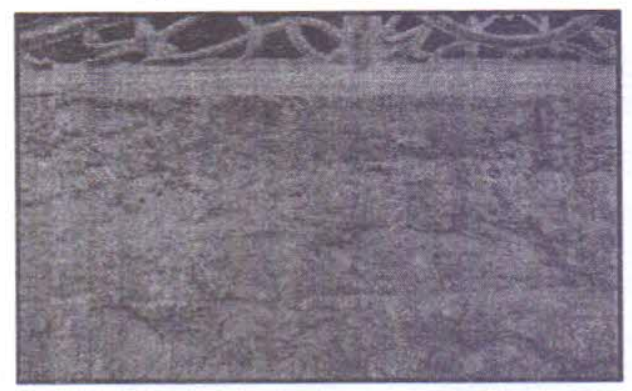

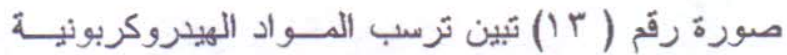

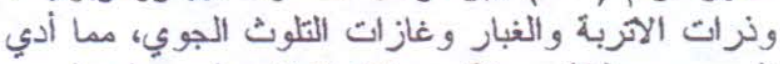

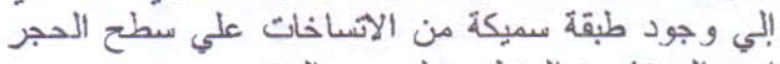
ادت اللي تشويه المنظر وطمس معالمه المنه (الو اجهة الجنوبية الشرقية من الخارجة )

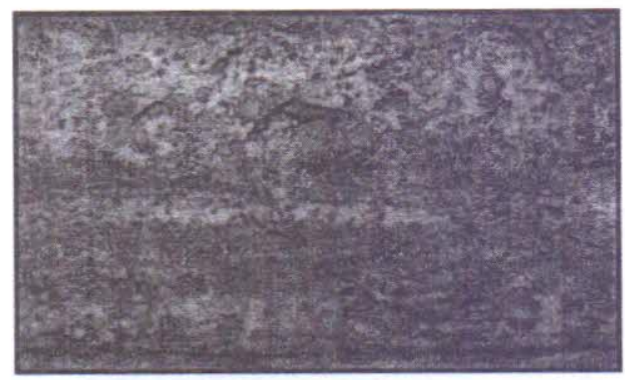

صورة رقم ( ع ا) تبين حدوث ثقوب وفجوات بسطح

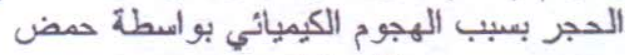
الكبريثيك، (اللو اجهة الشمالية الثرقية من الخارج ) (الكرجية )

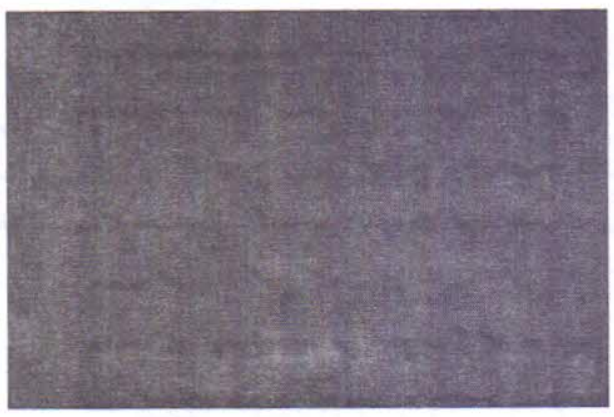

$$
\text { صورة رقم ( أ) تبين سطح الحجر قبل عملية }
$$

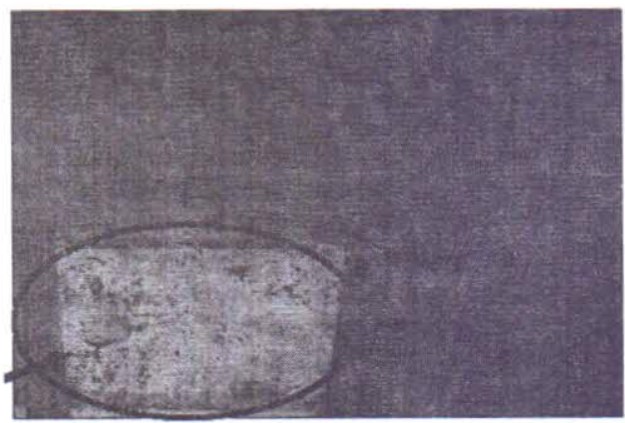
صورة رقم ( ب (1) تبين سطع الحجــر بعـد عمليـة النتظيف ( الوا اجهة الجنوبية الشرقية بالجامع)

